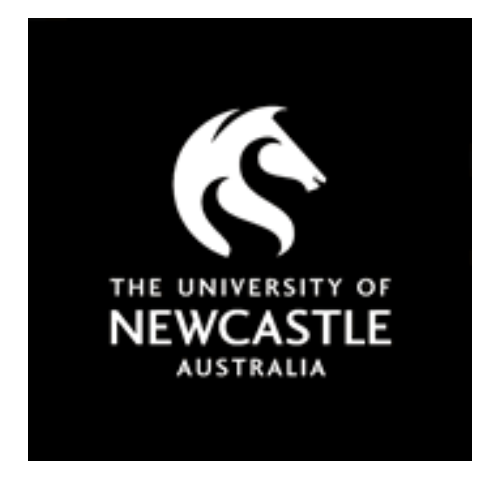

\title{
NOVA
}

University of Newcastle Research Online

nova.newcastle.edu.au

Sundberg, Frida; Barnard, Katharine; Rami-Merhar, Birgit; Smart, Carmel E.; Hanas, Ragnar; Cato, Allison; de Beaufort, Carine; DiMeglio, Linda A.; Dooley, Greg; Hershey, Tamara; Hitchcock, Jeff; Jain, Vandana; Weissberg-Benchell, Jill. "Managing diabetes in preschool children", Published in Pediatric Diabetes Vol. 18, Issue 7, p. 499-517. (2017)

Available from: $\mathrm{http}: / / \mathrm{dx}$. doi.org/10.1111/pedi.12554

This is the peer reviewed version of the above article, which has been published in final form at http://dx.doi.org/10.1111/pedi.12554. This article may be used for non-commercial purposes in accordance with Wiley Terms and Conditions for Self-Archiving.

Accessed from: http://hdl.handle.net/1959.13/1352902 


\section{Managing diabetes in preschool children}

ISPAD Clinical Practice Consensus Guidelines

Sundberg Frida, MD, PhD, The Queen Silvia Children's Hospital/Sahlgrenska University Hospital and Sahlgrenska Academy, Gothenburg University, Gothenburg, Sweden

Barnard Katharine Psychologist, PhD, Faculty of Health and Social Sciences, Bournemouth University, UK

Cato Allison, Psychologist, PhD, Neurology Division, Nemours Children's Health System, Jacksonville, FL USA

de Beaufort Carine, MD, PhD Clinique Pediatrique/CHL, Luxembourg, Luxembourg and Department of Pediatrics , UZ Brussels, Belgium

DiMeglio Linda A, MD, Department of Pediatrics, Section of Pediatric

Endocrinology/Diabetology, Indiana University School of Medicine, Indianapolis, USA

Dooley G, parent of a child with type 1 diabetes diagnosed at age 2, co-founder of the type 1 diabetes blog Inspired by Isabella (www.inspiredbyisabella.com)

Hershey Tamara, Ph D, Psychiatry, Neurology and Radiology Departments Washington University School of Medicine, Washington, USA

Hitchcock J, parent of a child with diabetes diagnosed at age 2, founder and president of Children with Diabetes (www.childrenwithdiabetes.com)

Jain Vandana, Department of Pediatrics, All India Institute of Medical Sciences, New Delhi, India

Weissberg-Benchell Jill, Psychologist, Northwestern University's Feinberg School of Medicine, Ann and Robert H. Lurie Children’s Hospital of Chicago, Chicago, USA

Rami-Merhar Birgit, MD, Department of Pediatric and Adolescent Medicine, Medical University of Vienna, Austria

Smart Carmel E, RD, PhD, Department of Endocrinology, John Hunter Children's Hospital and University of Newcastle, Newcastle, Australia

Hanas Ragnar, MD, PhD, Department of Pediatrics, NU Hospital Group, Uddevalla and Sahlgrenska Academy, Gothenburg University, Gothenburg, Sweden

This article is a new chapter in the ISPAD Clinical Practice Consensus Guidelines Compendium. The complete set of guidelines can be found for free download at www.ispad.org. The evidence grading system used in the ISPAD Guidelines is the same as that used by the American Diabetes Association. See page 3 in ISPAD Clinical Practice Consensus Guidelines 2014 Compendium: Pediatric Diabetes 2014; 15 (Suppl. 20):1-3)

\section{Recommendations}

- The target HbA1c for all children with type 1 diabetes, including preschool children, is recommended to be $<7.5 \%$ ( $<58 \mathrm{mmol} / \mathrm{mol})$ (B). 
- This target is chosen with the aim of minimizing hyperglycemia, severe hypoglycemia and reducing the likelihood of development of hypoglycemic unawareness (B).

- Intensive insulin therapy, i.e. as close to physiological insulin replacement with preprandial insulin doses and basal insulin, should be used, with frequent glucose monitoring and meal-adjusted insulin regimens. (C).

- Insulin pump therapy is the preferred method of insulin administration for young children (aged $<7$ years) with type 1 diabetes (E). If pump therapy is not available, multiple daily injections (MDI), preferably with an injection port, should be used from the onset of diabetes $(\mathrm{E})$.

- For preschool children using intensive insulin therapy, preprandial bolus insulin given for correction if blood glucose is high and for at least part of the meal is preferable to administering the whole dose during or after the meal (C).

- Carbohydrate counting is best introduced at onset of diabetes (E).

- The small insulin doses of preschool children may necessitate diluting insulin for precise dosing (E).

- Syringes with $1 / 2$ unit marking and pens with at least $1 / 2$ unit dosing capability should be used to facilitate more accurate insulin dosing if a pump is not used (or as a backup to pump use) (E).

- Continuous glucose monitoring (CGM) is the preferred method for adjusting insulin doses (E). If CGM is not available, 7-10 blood glucose tests/day are usually needed for satisfactory glucose control $(\mathrm{E})$

- Injection, infusion, and CGM sites should be properly prepared and regularly rotated in order to reduce the likelihood of scarring, infection, rashes, eczema and dry skin (E).

- Injection, infusion and CGM sites should be inspected by diabetes team members at every clinic visit to detect and treat any skin problems, such as lipohypertrophy or lipohypotrophy (E).

- The use of pumps and CGM are often limited by skin reactions to the adhesive. A skin moistener that preserves water can be used to prepare the site a few days prior to insertion. Topical cortisone (group I or II) can be used to treat eczema and to manage itching after removal (E).

- Life style interventions designed to reduce the risk of subsequent cardiovascular disease in children with type 1 diabetes are needed, and should be directed towards the entire family and not just the individual child with type 1 diabetes $(\mathrm{C})$.

- Family-centred meal routines with restrictions on continuous eating habits (grazing) are important to ensure dietary quality and optimize glycemic control in preschool children $(\mathrm{C})$.

- Diabetes education should be provided to staff at preschools and schools where children with type 1 diabetes are enrolled, in order to ensure that equal participation in all preschool/school activities occurs and is safely managed (E).

- Optimal glycemic control, involving the minimising of both hypo- and hyperglycemia will give the child/adolescent the best opportunity to concentrate, participate and learn whilst at preschool and school (C).

- It is essential to monitor weight and height on growth charts in all children with type 1 diabetes $(\mathrm{E})$.

\section{Introduction}


This chapter focuses on components of care unique to toddlers and preschool-aged children with type 1 diabetes. These guidelines are written in particular for children with type 1 diabetes aged 6 months to 6 years. Children $<6$ months of age at diagnosis should be suspected of having diabetes other than type 1 diabetes, including monogenic diabetes, and their management is discussed in the ISPAD guideline on "The diagnosis and management of monogenic diabetes in children and adolescents" (1).

Preschool children are dependent on others for all aspects of their care. For the families (primarily parents) of preschool children with type 1 diabetes, their diabetes teams, and other caregivers, including school and day care staff members and babysitters, treatment is a constant challenge. Yet, despite this hurdle, it is important to strive for normoglycemia, as current knowledge about the implications of dysglycemia makes reducing the likelihood of acute and chronic complications imperative from the time of diabetes onset. Optimizing glycemic control for children in this age group often requires treatment using strategies that differ from those employed for older children and adolescents with type 1 diabetes. These strategies need to take into consideration the cognitive, motor and social immaturity of preschool children as well as their small body size and growth pattern.

In addition to their dependence on others for insulin administration and glucose monitoring, preschool children are also dependent on others for aspects of their lifestyle related to healthy eating and engagement in physical activity. Lifestyle choices and preferences established during early childhood provide a window of opportunity for ingraining healthy habits that will be perpetuated throughout the child's life. The early establishment of positive behaviours is necessary to ameliorate the high risk of cardiovascular disease that is associated with diabetes. Providing adequate education and support of lifestyle changes requires that the multidisciplinary diabetes team uses a family-based approach to ensure that the whole family is appropriately supported.

Supporting the family is necessary for promoting health in the preschool child with type 1 diabetes. Early childhood is important for establishing the "salutogenic" (health promoting) capacity needed for a long life with type 1 diabetes (2). The core aspect of a person's salutogenic capacity is a good "sense of coherence", consisting of an everyday perception of comprehensibility, manageability and meaningfulness of health promoting actions taken in everyday life. The main sources of the child's salutogenic capabilities are the parents. Supporting the parents to endure the burden of intensified insulin treatment, including their need for counselling and sleep, is essential to promote and maintain the health and well-being of the child. It is also important to support the parents to involve the child in diabetes-related tasks such as helping to select finger for monitoring, site for injection/infusion, and to encourage age-appropriate positive problem solving strategies when diabetes-related problems occur.

Screening and promotion of optimal health related quality of life should be regularly undertaken in preschool children with type 1 diabetes as in any child with type 1 diabetes. In the research setting, it is important to use screening questionnaires validated in all pediatric age groups.

Children younger than seven years of age with type 1 diabetes constitute a minority of the population of all pediatric patients with type 1 diabetes. In small centres this will make the number of very young patients small and the time needed to gain experience in care of this 
patient group will be longer. Close collaboration between centres is necessary in order to optimize quality of care for preschool children with type 1 diabetes.

\section{Growth and development in the first years of life}

Growth and development in the first years of life are characterized by an intricate interplay between genetic, metabolic, hormonal and environmental factors. "Growth" is an increase in size of the body and its constituent organs. "Development" is the differentiation of the form and function of the organs, and refers to not only somatic development but also neurocognitive, and psychosocial development. Rapid changes in growth and development occur in the first years of life.

In the first year of life children grow $25-30 \mathrm{~cm}$, in the second year approximately $12 \mathrm{~cm}$, (comparable to the growth spurt in puberty) and in years 3-6 around 6-8 cm per year. Weight triples in the first year of life, increases by approximately $2.5 \mathrm{~kg}$ in the second year, followed by an increase of around $2 \mathrm{~kg}$ per year in the next 3-4 years. A peak in subcutaneous tissue mass is observed around 9 months of age, which subsequently decreases until 6 years of age. In order for preschool children to experience normal growth and development, it is essential that they maintain near normoglycemia, aiming to increase glucose time in range, and are provided with sufficient nutrients $(3,4,5,6)$. Restrictive diets or lack of food make it difficult to provide essential nutrients for growth and development, and should be avoided. It is essential to monitor weight and height on growth charts in all children with type 1 diabetes at every clinic visit.

This requirement of sufficient nutrition is in part due to the brain's high metabolic expenditure in infancy and childhood (three times higher than in adults). Body proportion at birth is characterized by a large head and prominent abdomen. After birth the brain and the cranium continue to grow and reach $4 / 5$ of the adult size by the end of the second year, growing much faster than many other body parts including the extremities (7).

\section{The brain and cognitive development in children with early onset type 1 diabetes}

The brain is metabolically highly demanding, accounting for $20 \%$ of the total energy requirement in adults (8). In the adult, the brain depends on a continuous supply of glucose as fuel. In the neonate, glucose is essential for different intracerebral pathways (9). Brain development requires different nutrients to support the five key processes: 1) neuron proliferation, 2) axon and dendritic growth, 3) synapse formation, pruning and function, 4) myelination, 5) neuron apoptosis. Regional and temporal variation in glucose utilization suggests that glucose is essential not only for energy production in the brain, but potentially for cellular proliferation and synaptogenesis as well (10). In the neonatal and infant brain, alternative energy sources may be identified such as ketone bodies, which are transported over the blood brain barrier in times of glucose shortage. The ketone bodies are a substrate for lipid synthesis, although not essential (11).

In addition to somatic growth, preschool children experience rapid cognitive development. Children start by investigating objects in their immediate environment, eventually expanding to exploring anything within reach. Mobility and thus physical activity increases with age. 
Multiple risk factors have been associated with potential suboptimal cognitive and fine motor development in children and adolescents with type 1 diabetes. These factors include early onset of disease (typically defined as $<5$ years of age) (12), disease duration, history of moderate to severe ketoacidosis (including those at diagnosis) $(13,14)$, severe hypoglycemia (including seizures or unconsciousness) (15), cumulative exposure to hyperglycemia, and possibly, the sex of child (16). A meta-analysis showed that the risk of cognitive disruption is largest for children with early-onset diabetes and that the effect is detectable after a mean diabetes duration of six years (17). The mean effect size is moderate but might not be large enough to affect school performance. Clinicians should be concerned about DKA, severe hypo- and hyperglycemia, all being detrimental for the health of the preschool child.

When reviewing these findings, it is important to distinguish between statistically significant group differences versus clinically significant findings. Statistically significant group differences may or may not translate into a functional impact on the daily life of a child, which has not been fully explored in children with type 1 diabetes. However, we know that early brain and cognitive development are important for later success in school and beyond.

Glucose uptake by the brain is insulin-independent and mainly driven by the concentration of glucose. This directly exposes the neuronal cells of the brain to oxidative stress and glucotoxicity in hyperglycemia, and to lack of fuel in hypoglycemia.

The maturation of grey matter in the brain is intense throughout the toddler and preschool years. Grey matter development slowly curtails over time beginning around puberty. In contrast, white matter maturation (that is necessary for processing speed and coordinated, fluid movements) continues until early adulthood $(18,19)$.

During toddler and preschool years, the brain is highly sensitive to metabolic disturbances, and potential abnormalities have repeatedly been identified in MRI studies of young brains exposed to glycemic extremes, as in type 1 diabetes $(20,21,22,23)$. The mechanisms by which early brain development is affected by type 1 diabetes are not clearly understood. Long-term exposure to hyperglycemia as well as hypoglycemia (especially with seizures) and oxidative stress caused by glycemic variability have been suggested as contributing factors. The main effects seem to occur in the early phase of the disease. It has been suggested that metabolic conditions such as hyperglycemia and ketoacidosis at diagnosis can be predisposing events that makes the brain more vulnerable to subsequent metabolic insults $(13,16)$.

Some, but not all, studies investigating cognition in childhood onset type 1 diabetes, report decrements in the domains of IQ (Verbal IQ in particular), executive functions (attention, working memory, response inhibition), delayed memory (episodic recall), and processing speed (paper-pencil); however, these differences are generally not reported until the children are studied later in childhood $(24,25)$. One possibility is that chronic exposure to different aspects of dysglycemia is additive, and that brain and cognitive changes only become apparent over time.

Studies that specifically target the youngest children with type 1 diabetes have found only modest differences in cognitive function compared to peers. Among a large group $(n=144)$ of children aged 4 to $7 \mathrm{yrs}$, small differences in the following areas were reported: IQ, especially verbal, executive functions and internalizing mood disorders (26). The cognitive differences remained when controlled for parental IQ and level of internalizing mood disorders. Longitudinal follow up of these children is ongoing and may reveal how these differences 
change with time, further exposure to diabetes (including hypo- and hyperglycemia), and brain development (27).

A young child who has executive functioning difficulties, language/literacy deficits, slowed processing speed, or fine motor coordination difficulties will likely require professional attention at some point in their youth. Typically, these children are referred to a neuropsychologist or other learning specialist during the early elementary years. These children can require specialized tutoring, small group instruction, support in the classroom or other assistance. For all children with cognitive development issues, early identification and remediation are crucial to avoid poor outcomes. Optimal glycemic control will give young children with type 1 diabetes the best opportunity to concentrate, participate and learn whilst at preschool and school. By achieving good glycemic control, including mitigating prolonged exposure to hyperglycemia, and by providing early identification and intervention for academic, cognitive or motor issues, health care professionals are best able to help children avoid any negative impact of type 1 diabetes on everyday function.

For further reading the ISPAD guideline on psychological care of children and adolescents with type 1 diabetes comprehensively addresses this subject (28). See also the ISPAD Guideline on hypoglycaemia (29).

\section{Glycemic targets and control in preschool children with type 1 diabetes}

Optimizing glycemic control for preschool children with type 1 diabetes is crucial for their future, both with respect to acute and long-time diabetes complications as well as their neurocognition, brain structure and health-related quality of life (HRQoL).

ISPAD published glycemic targets for $\mathrm{HbA1c}(<7.5 \%$; $<58 \mathrm{mmol} / \mathrm{mol})$ and for SMBGs (from optimal to high risk) in the latest guidelines 2014 (30). See Table 1. The targets are applicable to all pediatric age groups, including preschool children, and the aim should be to achieve optimal glycemic control. The American Diabetes Association (31) in 2014 redefined blood glucose targets for all pediatric age groups to be at the same level as ISPAD (32). In UK, glycemic targets for all pediatric age groups are recommended in the NICE guidelines, recently updated to an even lower HbA1c level of $6.5 \%$ (48 mmol/mol) (33).

\begin{tabular}{|c|c|c|c|}
\hline & ISPAD (32) & ADA (31) & NICE (33) \\
\hline $\begin{array}{l}\text { Preprandial glucose } \\
\text { target }\end{array}$ & $\begin{array}{l}4.0-8.0 \mathrm{mmol} / \mathrm{l} \\
(70-145 \mathrm{mg} / \mathrm{dL})\end{array}$ & $\begin{array}{l}5.0-7.2 \mathrm{mmol} / \mathrm{l} \\
(90-130 \mathrm{mg} / \mathrm{dL})\end{array}$ & $\begin{array}{l}4.0-7.0 \mathrm{mmol} / \mathrm{l} \\
(72-126 \mathrm{mg} / \mathrm{dL})\end{array}$ \\
\hline $\begin{array}{l}\text { Postprandial glucose } \\
\text { target (two hours } \\
\text { post meal) }\end{array}$ & $\begin{array}{l}5.0-10.0 \mathrm{mmol} / 1 \\
(90-180 \mathrm{mg} / \mathrm{dL})\end{array}$ & & $\begin{array}{l}5.0-9.0 \mathrm{mmol} / 1 \\
(90-162 \mathrm{mg} / \mathrm{dL})\end{array}$ \\
\hline Bedtime & $\begin{array}{l}6.7-10 \mathrm{mmol} / \mathrm{l} \\
(120-180 \mathrm{mg} / \mathrm{dL})\end{array}$ & $\begin{array}{l}5.0-8.3 \mathrm{mmol} / \mathrm{l} \\
(90-150 \mathrm{mg} / \mathrm{dL})\end{array}$ & \\
\hline Overnight & $\begin{array}{l}4.5-9.0 \mathrm{mmol} / \mathrm{l} \\
(80-162 \mathrm{mg} / \mathrm{dL})\end{array}$ & & \\
\hline $\mathrm{HbA} 1 \mathrm{c}$ target & $\begin{array}{l}<58 \mathrm{mmol} / \mathrm{mol} \\
(<7.5 \%)\end{array}$ & $\begin{array}{l}<58 \mathrm{mmol} / \mathrm{mol} \\
(<7.5 \%), \text { a lower } \\
\text { target of }<53 \\
\mathrm{mmol} / \mathrm{mol} \text { can be set }\end{array}$ & $\begin{array}{l}<48 \mathrm{mmol} / \mathrm{mol} \\
(<6.5 \%)\end{array}$ \\
\hline
\end{tabular}


if it can be achieved

without

hypoglycemia

It is important that the diabetes team and family share the same target HbA1c and glucose ranges. Otherwise there is a high risk of discrepancy that can go both ways. Sometimes parents strive for lower glucose levels than the diabetes team, who at times may articulate that the family is too strict and take too many glucose tests, especially at night. At other times, the parents have their own set of higher glucose targets that they feel fit better with their daily life, finding the targets set by the health care team unachievable.

When evaluating glycemic targets together with the family, it might be useful to express them as time spent within target and time below or above target. It is important that both the diabetes team and the families consequently use a language that tells the child that a glucose value can be high, low or normal, and that the glucose level is never "bad". The knowledge of a glucose value often calls for action, but never for blaming or punishing the child.

* Parents express that diabetes management style can make a difference. A positive, nonjudgmental, attitude will likely have a positive influence on the way a young child views and manages his/her type 1 diabetes as he/she gets older. Parents should be encouraged to adopt a 'matter-of-fact' approach to the routines (injections/ pump site changes, finger pricks and meal times), treating numbers as just numbers/data points, and not apologizing for aspects of care such as finger pricks, site changes, injections that cannot be avoided.

Maximizing the amount of time glucose values are in range needs to be the target for multidisciplinary diabetes teams, as well as the family/caregivers. Diabetes education $(34,35)$ and a clearly set glycemic target (36) are very important $(37,38)$. Age specific challenges need to be considered and age-appropriate actions taken to achieve these.

As discussed above, there are detrimental effects of hyperglycemia; yet it is an existing practice to allow blood glucose levels to reach the hyperglycemic range in the youngest age group in order to avoid hypoglycemia at all costs. This is unsafe and treatment should instead aim to minimize both hyperglycemia and hypoglycemia in the effort to achieve (near) normoglycemia. If the diabetes team is inexperienced in treating preschool children with type 1 diabetes, support and advice should be sought from more experienced colleagues.

It might not just be the HbA1c level that is important. Glycemic variability also seems to play a role in the development of diabetic complications $(39,40)$, but the long term impact of glycemic variability remains controversial $(41,42)$. Data from adults using CGM show a deleterious role of glycemic variability, in that in groups with comparable HbA1c, those with complications had a SD of $4.1 \mathrm{mmol} / \mathrm{l}$ while those without complications had a significantly lower SD of $3.4 \mathrm{mmol} / \mathrm{l}(43)$.

Age-specific, family-centered diabetes education plays a key role in achieving metabolic targets, together with flexible insulin regimens, glucose monitoring and carbohydrate counting $(30,34,44)$.

Hyperglycemia is a major risk factor for (recurrent) ketoacidosis (44) and microvascular complications later in life $(46,47)$. 
Long-term tracking of glycemic control from childhood until adulthood has been reported (48, $49,50,51,52)$. These observations indicate a clear correlation between the HbA1c achieved within the first few months after diabetes diagnosis, the glycemic control later in life and the risk for cardiovascular complications. The lower the HbA1c achieved at an early phase of life with diabetes was, the lower the HbA1c was later on.

Long-term studies, e.g. the DCCT-EDIC, describe a prolonged effect of prior glycemic levels on diabetic complications, called glycemic memory. This effect is independent of more recent glycemic control. The DCCT showed a significant difference of around 2\% in HbA1c between the intensive and conventional groups, but 1 year after the closeout of the study, HbA1c levels were approximately the same (around 8\%) $(46,47)$. Nevertheless, the intensive group showed fewer microvascular complications, with a risk reduction in retinopathy even 18 years after the end of the study (53). The DCCT-EDIC results have led to the recommendation of early tight glycemic control to reduce the risk for diabetic microvascular and macrovascular complications $(47,54,55)$. The ISPAD guideline on microvascular and macrovascular complications provides a more detailed discussion (56).

Early onset of diabetes at a very young age will lead to a longer duration, which in itself is associated with a higher lifelong risk of complications, compared to persons with later onset type 1 diabetes (57). So far, conflicting data exist to whether the prepubertal years contribute to the same degree as the pubertal years for the development of microvascular complications (58). Sub-optimal metabolic control in children with early prepubertal diabetes onset may further contribute to the risk of complications. $(59,60,61)$. Persons with poor glycemic control during childhood have a high risk of long-term complications, even if substantial improvement is achieved as young adults (62), and NICE emphasizes the need to reduce the risk of long-term complications of type 1 diabetes in a population that will have a long duration of diabetes because the condition starts before adulthood.

\section{Insulin therapy in preschool children.}

Insulin treatment guidelines for preschool children are essentially similar to older children and adolescents (see Danne et al ISPAD guidelines for further reading on insulin and insulin analogs in pediatric use, 63), but age-dependent aspects have to be taken into consideration. Worldwide, most preschool children with diabetes use insulin injections to manage their diabetes. Although for many of these children insulin pump use should be considered, injection therapy is used in many centres in the following instances: early in the course of the disease in their remission period; children who were using an insulin pump but have experienced pump failures; and if living in limited resource settings where insulin pumps are unavailable.

Approval of insulin analogs in different age-groups is regulated by authorities. Two examples are the European Medicines Agency (EMEA) (www.ema.europe.eu) approvals and the U.S. Food and drug administration (FDA) (www.fda.gov) as of January 2016 (Table 2).

\begin{tabular}{|lll|}
\hline & $\begin{array}{l}\text { Approved by EMEA from } \\
\text { age }\end{array}$ & $\begin{array}{l}\text { Approved by FDA for } \\
\text { (studied from age) }\end{array}$ \\
\hline Insulin lispro & "adults and children" & $\begin{array}{l}\text { "adults and children" } \\
\text { (3 years) }\end{array}$ \\
Insulin aspart & $\geq 2$ years & $\begin{array}{l}\text { "adults and children" } \\
\text { (2 years) }\end{array}$
\end{tabular}




\begin{tabular}{|c|c|c|}
\hline Insulin glulisine & $\geq 6$ years & $\begin{array}{l}\text { "adults and children" } \\
\text { (4 years) }\end{array}$ \\
\hline Insulin detemir & $\geq 1$ year & $\begin{array}{l}\text { "adults and children" } \\
\text { ( } 2 \text { years })\end{array}$ \\
\hline Insulin glargine & $\geq 2$ years & $\begin{array}{l}\text { "adults and pediatric } \\
\text { patients" ( } 6 \text { years })\end{array}$ \\
\hline Insulin degludec & $\geq 1$ year & $\begin{array}{l}\text { "adults" } \\
\text { (18 years) }\end{array}$ \\
\hline
\end{tabular}

When using injections for insulin delivery, pain can be reduced by usage of subcutaneous catheters changed every third day (Insuflon ${ }^{\circledR}$ or I-port $\left.{ }^{\circledR}\right)(64)$.

\section{Insulin dosing}

Preschool children with optimal glycemic control usually need somewhat less insulin than older children. The total insulin dose has been reported to be $0.4-0.8 \mathrm{U} / \mathrm{kg} /$ day (median 0.6 $\mathrm{U} / \mathrm{kg} / \mathrm{day}$ ) in preschool children with well controlled type 1 diabetes after the remission phase (65). Insulin pumps offer both greater flexibility in insulin dosing and a better means to deliver very small, precise doses of insulin than when using injections (66), and are thus considered the preferred method for insulin delivery in infants, toddlers and preschoolers with diabetes, although earlier randomized studies have failed to show an effect on glycemic control (63). If pump therapy not is available due to lack of economic resources, multiple daily injections (MDI), preferably with an injection port, can be used. If the diabetes team is not experienced enough in pump treatment of preschool children, advice should be sought from a more experienced center to optimize quality of care.

\section{Basal insulin}

The low requirement of insulin and tendency toward low blood glucose levels are often most obvious during the night and especially between 3-6 am. Preschool children often need much more insulin late in the evening between 9 pm-12 midnight $(67,68,69)$. This creates typical patterns when programming the basal rates of an insulin pump used by a preschool child. The combination of the low body weight, and thus low total insulin dose, demands special consideration when using commercially available insulin pumps. A pump with a very high precision in delivering very small basal rates should be chosen for a preschool child.

Sometimes further reduction in the dose is needed, necessitating dilution of the current $U 100$ insulin $(65,70,71)$, or an intermittent basal rate of $0 \mathrm{U} / \mathrm{h}$ for limited periods i.e. every second hour during the night. Neither of the strategies is optimal, and the planning of the child's insulin treatment has to be carefully discussed (with advantages and disadvantages) with the parents so they are well aware of the benefits and risks of the chosen strategy. The given insulin should always be prescribed and documented in normal units to avoid hazardous misunderstandings regarding insulin dosing, especially if the child is admitted to hospital. A pump containing diluted insulin should be labelled with information regarding the currently contained concentration of insulin. (See table 3). 


\begin{tabular}{|c|c|c|}
\hline & Advantages & Disadvantages \\
\hline $\begin{array}{l}\text { Diluted insulin (ie } 10 \mathrm{U} / \mathrm{ml} \\
\text { or } 50 \mathrm{U} / \mathrm{ml} \text { ) }\end{array}$ & $\begin{array}{l}\text { Fine tuning of basal rates } \\
\text { is possible. } \\
\text { - All technical features of } \\
\text { pump can be used, such } \\
\text { as temporary basal rate } \\
\text { changes and bolus } \\
\text { calculations. } \\
\text { - Possible to set extremely } \\
\text { low basal rates. }\end{array}$ & 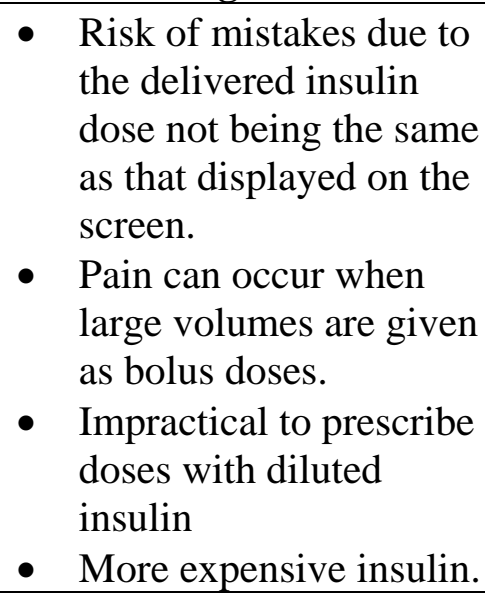 \\
\hline $\begin{array}{l}\text { "Empty" hours without } \\
\text { basal rate. }\end{array}$ & $\begin{array}{l}\text { - The pump gives exactly } \\
\text { the doses displayed on } \\
\text { the screen, decreased risk } \\
\text { of mistakes in dosing for } \\
\text { instance when insulin is } \\
\text { given temporarily with } \\
\text { pen. } \\
\text { - Use of more stable } \\
\text { commercially available } \\
\text { insulins is possible. }\end{array}$ & $\begin{array}{l}\text { Increased risk of } \\
\text { occlusion in tubing due } \\
\text { to low flow rate. } \\
\text { - Increased risk of ketosis } \\
\text { due to planned hours } \\
\text { without insulin. } \\
\text { - Impossible to make use } \\
\text { of technical features of } \\
\text { the pump as temporary } \\
\text { change of basal rate. }\end{array}$ \\
\hline
\end{tabular}

Table 3. Different strategies for delivering minute basal rates. No pumps that are available today can adjust the insulin concentration. Thus, if using diluted insulin, recommended doses from the bolus calculator must be recalculated to the diluted concentration.

A glucose and meal-adjusted basal-bolus insulin regimen (delivered by injections or pump) requires that the basal rate can be fine-tuned by the parents in accordance with the child's current insulin sensitivity. Insulin sensitivity can be increased after very active days, such as a day at the beach or out in the snow (decreased insulin resistance). The overnight basal might then be reduced with 10-30\% when using a pump or a similar decrease in bedtime long-acting insulin. Insulin sensitivity can be markedly reduced (increased insulin resistance) for example during fever when basal rate might be increased by $20-100 \%$ according to plasma glucose levels when using a pump, or a daytime increase in long-acting insulin. Under these circumstances, glucose levels have to be extremely carefully monitored and parents need constant access to support from the diabetes team.

When using injections for insulin treatment, the special diurnal pattern of insulin requirements in preschool children should be taken into consideration in designing an individualized basal dosing scheme. The need of insulin is very low in the early morning and high in the late evening, affecting the timing, dose of basal insulin and choice of insulin preparation. With MDI (multiple daily injections), a basal insulin analog can reduce hypoglycemia, including night-time hypoglycemia, compared to NPH insulin $(72,73,74)$. 


\section{Bolus dosing}

Although still often used, twice daily insulin dosing in this age group does not give the flexibility needed in adapting doses to varying situations in daily life. It is difficult to finetune, and difficult for the family to understand and adjust on their own, which is a necessity for a successful insulin treatment. A glucose and meal-adjusted basal-bolus insulin regimen (delivered by injections or pump) can be adapted to the preschool child's daily activities, and is the preferred type of insulin treatment.

Preschool children often need proportionally larger bolus doses than older children, often constituting 60-80 \% of the total daily insulin dose (TDD). The often used rule of 500 (500/TDD = how many grams of carbohydrate is covered by one $\mathrm{U}$ of insulin) for bolus calculations, as detailed in the ISPAD guideline on insulin therapy (63) rarely fits the youngest children as it often underestimates the insulin dose $(72,75,76)$. Different strategies can be used; either use 330 or 250 rule (gives 50-100\% more insulin) instead of 500, or, which is preferable, to observe and calculate the correct proportion between insulin and carbohydrates from real life meals. To calculate the insulin to carbohydrate ratio from a given meal, divide the carbohydrate content in the meal (in grams) by the insulin dose in units that gives an appropriate glucose profile after the meal. The need for insulin at breakfast is often very high, and one might consider using 150/TDD in the calculation, or calculate from real life meals as above.

The timing of the prandial bolus is important. As outlined in the review by Bell et al (77), several studies show that preprandial bolus insulin is preferable to insulin administered during or after the meal and should thus be routinely advised for all toddlers and pre-schoolers, even the most unpredictable eaters. However, the dose can be split into one pre-prandial and one during the meal when eating is erratic or new foods are offered.

The dose given during the meal can be based on what the parent estimates the child will eat of the remaining meal, taking into consideration the food that has just been eaten and the child's remaining appetite. Small inaccuracies in calculation of up to 5-7g carbohydrate will usually not be problematic (78). Larger inaccuracies may result in possible hypo- or hyper-glycemia 2-3 hours after eating, but not immediately (79). These can be anticipated and treated with additional carbohydrate or a small correction dose of insulin. With a pump, a combination bolus (also called combo or dual wave bolus) can be helpful, i.e. part of the bolus is given before the meal and the remainder over 20-40 minutes. If the child stops eating before the meal is finished, the remainder of the bolus can be suspended.

When giving these relatively large bolus doses, one must remember that they interact with the need for basal insulin in the following hours. Thus, the total basal rate can be relatively low, around $20-40 \%$ of TDD. In preschool children, it is often estimated that the effect of a subcutaneous given bolus of rapid acting insulin analogues (e.g. as lispro, aspart, or glulisine) lasts for only 2-3 hours (active insulin time in pumps) (80).

At breakfast there is often some degree of insulin resistance, and it is common to experience a marked blood glucose peak after breakfast in spite of an adequate insulin dose taken before the meal. The nutritional content of the breakfast has to be discussed and planned by the dietitian, together with the parents. Increasing the insulin dose (lower insulin-to-carbohydrate ratio) too much can risk hypoglycemia before lunch. In this situation, it may be helpful to give the prandial insulin 10-20 minutes before breakfast. The need for a large bolus dose insulin to cover breakfast might necessitate a very low or suspended basal rate during the following 3 hours. For some children, a small amount of fruit (5-10g of carbohydrates) may be given 2 
hours after breakfast (without insulin) to avoid hypoglycemia, but it is preferable not to establish a practice that necessitates skipping a bolus as this may continue as the child gets older.

When using multiple daily injections (MDI) with frequent blood glucose testing and mealadjusted insulin dosing, one possible strategy is to give a rapid-acting insulin analog for all meals, with the exception of the last meal of the day when short-acting regular insulin can be used to meet the increase in blood glucose before midnight.

\section{Nutritional needs of the preschool child with type 1 diabetes}

Breastfeeding should be encouraged for all infants, including infants with diabetes (WHO recommendation, www.who.int). Complementary foods, preferably iron-rich, should be commenced from 4 to around 6 months of age (81). If breastfeeding is not possible, an ironfortified infant formula should be given as the main milk drink until 12 months of age.

A routine regarding breast- or formula-feeding is important for infants with diabetes as this enables appropriate interpretation of blood glucose levels and basal and bolus insulin adjustments. This may involve 3-4 hourly feeds (of approximately 150-240ml) during the day with complementary solids. Continuous or hourly breastfeeding is discouraged as this makes insulin dosing difficult. Breast milk has approximately $7.4 \mathrm{~g}$ carbohydrate $(\mathrm{CHO})$ per $100 \mathrm{ml}$; so for infants 6 months and older it is possible to bolus before the feed for at least $5-7 \mathrm{~g} \mathrm{CHO}$ and $15 \mathrm{~g} \mathrm{CHO}$ in older babies ( $>9$ months).

Optimal nutrition is required to provide sufficient energy and nutrients to meet the rapidly changing needs of children in this stage of life. Dietary recommendations are based on healthy eating principles suitable for all preschool children, with the aim of establishing family based meal-time routines that promote glycemic control and reduce cardiovascular risk factors. Carbohydrate counting is important to permit the matching of insulin dose to carbohydrate intake on intensive insulin regimens (44), and should be taught to the family at the onset of diabetes. Nutritional advice must be individualised and adapted to cultural and family traditions. A pediatric diabetes dietitian should provide education, monitoring and support at regular intervals throughout the preschool years, as parents of preschool children with diabetes report meal-times as one of the most difficult components of their child's care (82).

There is international agreement that carbohydrate should not be restricted in children with type 1 diabetes as it may result in deleterious effects on growth. Care should be taken when giving dietary education that methods of quantifying carbohydrate do not increase total fat and/or saturated fat intake (44). Although caregivers may prefer high-fat snacks to avoid affecting glucose levels, this should be discouraged as they will provide unnecessary calories, an unhealthy fat intake and negatively impact dietary quality.

Preschool children with type 1 diabetes should consume a diet that emphasizes fruit, vegetables, whole grain bread and cereals, dairy foods and appropriate types and amounts of fats. Low fat diets are not suitable for children under two years of age. Lower glycemic index (GI) choices, such as wholegrain bread and cereals can be introduced as substitutes for higher GI food choices from two years of age. Iron deficiency can be a concern in this age group; adequate consumption of lean meat or alternatives is important and should not be over-looked because of the increased focus on carbohydrate. 
A guide to the macronutrient distribution of the total daily energy intake in preschool children is as below. However, this should be based on an individualized assessment.

- Carbohydrates: 45-55 Energy (E) \% (44, 83). Average intakes $150 \mathrm{~g} /$ day in children aged $1 \frac{1}{2}-3$ years. $200 \mathrm{~g} /$ day in children $4-10$ years $(84)$.

- Protein: $15-20 \mathrm{E} \%$ (decreasing with age from approximately $1.5 \mathrm{~g} / \mathrm{kg}$ body weight $/$ day in six month old infants to $1 \mathrm{~g} / \mathrm{kg}$ body weight/day in preschoolers) (85)

- Fat: 30-35 E \% (less than10 E\% saturated fat, less than $10 \mathrm{E} \%$ polyunsaturated fat, and more than $10 \mathrm{E} \%$ mono-unsaturated fat). Infants less than 12 months may consume up to $40 \%$ energy from fat.

It is important to encourage all children, including children with type 1 diabetes, to eat plenty of fruit and vegetables. Recommendations state $180 \mathrm{~g}$ vegetables and $150 \mathrm{~g}$ fruit daily from 2 years of age $(84,86)$ or $400 \mathrm{~g}$ fruit/vegetables each day from 4 years of age $(83)$.

Research has shown the dietary quality of preschool children with diabetes is poorer than their healthy peers (87). Studies have shown that preschool children with type 1 diabetes consume less fruit and vegetables and have higher saturated fat intakes than peers (88) than recommendations would advise $(87,89)$. Poor food intake may increase the risk of cardiovascular disease. Eating habits in young children can influence food choices later in life (90), so early intervention with increased attention to an increase in fruit and vegetable intake and decrease in saturated fat is needed. Just like healthy children, children with diabetes may require up to 10 exposures to a new food before it is accepted (91).

Several studies show that children with type 1 diabetes are more overweight compared with children in the general population $(89,92)$, with the youngest children $(<6$ years $)$ being the most overweight $(93,94)$. It is important to plot the growth chart including assessments of weight for length or height regularly to identify excessive weight gain, in order to commence interventions that involve the whole family. Encouraging participation in family meals has been recommended to promote dietary quality (95) and social interaction.

Age-appropriate finger foods should be encouraged for self-feeding, and the reintroduction of a bottle as an easy method of carbohydrate intake discouraged. Bottles can lead to overconsumption of fluids, increasing carbohydrate intake and placing other nutrients at risk.

\section{Establishing positive food behaviours and meal-time routines}

Establishing positive food behaviours and meal-time routines are important for preschool children with type 1 diabetes, as these behaviours impact glycemic control $(82,96)$ and encourage life-long nutrition practices (90). Normal early childhood development, including seeking independence, transient food preferences, variable appetite, food refusal and behavioural resistance often make meal times challenging for parents and carers. Parents of children with type 1 diabetes report more disruptive meal behaviours, including longer meal duration and more frequent food refusal compared to controls $(97,98)$; even for children using insulin pump therapy (99). Research has demonstrated positive correlations between suboptimal dietary adherence and higher blood glucose levels $(82,88,99,100)$. Caregivers' fear of hypoglycemia associated with food refusal or unpredictable dietary patterns can result in force feeding, grazing continually over the day and postprandial insulin administration, causing prolonged periods of hyperglycemia. 
Family-centred meals are important to model eating practices and to encourage new foods. For small children, meal times should be limited to approximately 20 minutes per meal (101). Conventional insulin regimens require adherence to a structured plan of carbohydrate intake, and parents frequently report problems with this approach (82). Intensive insulin management offers greater flexibility in meal timing and carbohydrate quantities.

To assist the reliable intake of carbohydrate at meal-times and to minimise food refusal, the following strategies should be advised: structured meal-times, avoidance of continuous eating habits, small snacks including limits on low carbohydrate foods as these fill the child up, limits on the time spent at the table, avoidance of force feeding, and reassurance by all team members regarding the usual non-severity of hypoglycemic episodes related to inadequate carbohydrate consumption. Parents or carers should be reassured that under- or overconsumption of carbohydrate by 5-7 $\mathrm{g}$ is unlikely to cause significant hypo- or hyperglycemia $(78,79)$. Parents should be advised that postprandial bolus insulin is problematic as it can become an established habit and also reinforces anxiety about the child under-eating. Fear of hypoglycemia can also lead to under-bolusing for meals, resulting in inadequate bolus doses given over the day and subsequent hyperglycemia. Continuous eating (grazing) makes interpretation of blood glucose levels and insulin dose adjustments difficult. A regular meal pattern with one small snacking episode between meals ( 7 to $15 \mathrm{~g} \mathrm{CHO}$ ) will assist with preventing food refusal as the child will be hungrier at main meals. A dietitian should advise regarding age appropriate carbohydrate amounts as it is necessary to ensure the anticipated carbohydrate intake is reasonable based on age, growth and the child's previous intake. Unreasonable expectations of a child's intake may result in food refusal and subsequent hypoglycemia. Food refusal should generally be dealt with effectively and similarly to toddlers without diabetes. Preschool children becoming increasingly independent can recognise parental stress and quickly learn to use their diabetes as a way of getting their favourite foods. It is important to emphasise parental patience and to encourage parents not to use food bribes.

All diabetes team members should provide the family with clear and consistent messages regarding food and meal-time behaviours. Distractions such as the television and toys should be removed at mealtimes. Research has demonstrated that disruptive child behaviours can be reduced by establishing specific rules and consequences for mealtimes and teaching parents behavioural strategies for meals (102).

There is consensus that continuation of support by a pediatric dietician throughout childhood and adolescence is essential for optimal care.

* In parental experience, it can be difficult at times to give pre-prandial bolus doses of insulin due to the fear of food refusal and resultant hypoglycemia. Strategies to handle this need to be discussed with the parents (as above) and the risk of all aspects of dysglycemia following postprandial bolus doses need to be explored.

* Should a child have a high blood glucose because of eating something unplanned, a calm explanation of the need to cover food with insulin is necessary.

\section{Lifestyle factors in preschool children}


The American Heart Association (AHA) has identified certain childhood conditions (including type 1 diabetes) associated with extremely high risk of cardiovascular disease, calling for treatments to minimise this risk (103).

Lifestyle habits, such as nutritional preferences (90), physical activity (104) and time spent sedentary (105), that are established in childhood have a great propensity to follow into adulthood. Thus, lifestyle factors in early childhood have a dual impact on later cardiovascular risk, observable both as early markers of atherosclerosis during adolescence (106) and also as a set of behaviours that influences the child's risk of cardiovascular disease as an adult and even into senescence.

Children tend to follow the lifestyle habits of their parents and entire family regarding physical activity (107), TV watching (108) and food choices $(109,95,110)$, and this has been found to influence children's food habits throughout their lives (90). Lifestyle supporting interventions should thus be directed towards the parents and entire family and not the individual child with T1DM.

There is no contradiction between population-based interventions to promote increased physical activity or healthier food choices in all children and interventions that are routinely part of the diabetes care delivered by the diabetes team. Preschool children with type 1 diabetes could benefit from both efforts, but targeted interventions are necessary to meet the specific needs of children with type 1 diabetes.

\section{Physical activity}

Physical activity confers many health benefits for healthy children. A strong graded inverse cross-sectional association has been observed between physical activity and insulin resistance $(111,112)$ and body fat $(113)$. Spending more time in moderate and vigorous physical activity is associated with decreased cardiometabolic risk factors in children (114). When designing physical activity interventions to reduce the risk of cardiovascular disease in children, including children with type 1 diabetes it is important to focus on high-intensity physical activity to be most effective (114). Engaging in regular physical activity is also necessary in order to acquire and improve gross motor skills (115).

Many countries recommend at least 60 minutes per day of moderate and vigorous physical activity for all children (116), and WHO recommends this at least from five years of age (www.who.int). Some countries have changed their recommendations for physical activity in preschool children from 60 minutes of moderate and vigorous physical activity to 180 minutes of any intensity of physical activity per day (www. health.gov.au, 117). This change of recommendation has been questioned because the reduction in the risk of cardiovascular and metabolic problems might be too low with lower intensity of physical activity $(113,114)$.

It has been shown that outdoor playing and especially spacious outdoor playing environments are associated with increased physical activity in preschool children (118). Asking families about the amount of time spent playing outdoors can be a useful way to quantify the physical activity of a preschool child with type 1 diabetes.

Physical activity should be promoted in all children with type 1 diabetes. Both having diabetes and being a girl has been reported to be associated with lower levels of physical 
activity in preschool children with type 1 diabetes, indicating that particularly young girls with type 1 diabetes are at high risk of being too physically inactive (118).

\section{Practical monitoring of glycemic control}

\section{Plasma glucose (SMBG)}

Glycemic control is often evaluated with plasma glucose monitoring (SMBG). All families with a child with diabetes should be taught how to measure and interpret glucose values. A high precision glucometer (error less than 10\%) should be used in preschool children, both when relying on SMBG for glycemic monitoring and when using the glucometer for calibration of CGM. Accuracy in everyday monitoring situations should be ensured by follow-up with the diabetes team. This shall include education on the importance of ensuring that the fingertips are clean and dry before monitoring plasma glucose. The child should be introduced to glucose monitoring and interpretation according to age appropriate and individual capabilities. The development of the mathematical understanding of numbers and time is gradual.

Most children with type 1 diabetes should by the age of seven years be capable of taking glucose tests and performing some basic interpretation of plasma glucose levels under supervision. However, this should always be overseen by a parent or other caregiver, since independent self-care is not expected from any preschool child with type 1 diabetes.

General advice on SMBG monitoring is available in the ISPAD Guidelines on Assessment and monitoring of glycemic control (30). In children younger than seven years of age, the recommended testing frequency of 4-6 times per day is rarely sufficient when striving for normoglycemia. Even with a higher testing frequency of 7 or 10 tests per day, the number of undetected hypo- and hyperglycemic events in insulin treated preschool children are high $(120,121)$.

Observational studies from different countries show that a common frequency of SMBG in preschool children with type 1 diabetes is 7-10 tests per day $(121,122)$. Nighttime SMBG is recommend by many diabetes teams, and performed by most families with preschool children, (123). Preschool children with diabetes can spend long time in the hypoglycemic range without detection despite night-time monitoring of SMBG (121).

Many parents are sleep-deprived due to night-time testing of plasma glucose $(123,124)$. The normal activities of the child have to be interrupted in order to measure a plasma glucose value during daytime. Thus, SMBG has several limitations as method of monitoring glycemic control.

\section{Continuous glucose monitoring (CGM)}

When available, CGM with alarms is generally the preferred method for monitoring of glucose levels in children younger than seven years of age with type 1 diabetes. CGM should be available and utilized as a tool for adjusting insulin doses.

- Data on CGM use in preschool children are limited, but suggest low overall rates of use $(125,122)$, often due to financial constraints.

- Parental satisfaction with CGM use is high, in large part because the technology can decrease the likelihood of severe hypolycemia (126). 
- When parents/caregivers share their thoughts and interpretations, real-time CGM information, including a colour coded screen with arrows, and alarms can often be well understood by preschool children.

- CGM device use in preschool children can be hampered by issues of adhesion and skin irritation (127).

- The ability of some CGM devices to remotely transmit glucose values to a phone can be of benefit for parents/caregivers who rely on others for part-time care of their child with diabetes.

- CGM enables deepened analysis and understanding of glycemic patterns (such as postprandial glycemic excursions), and downloading data from the device is a pedagogic tool for the team when discussing solutions to various problems with the parents of a child with diabetes.

- Downloading at home by parents should be encouraged, and can form a basis for selfadjustment of insulin doses for experienced families.

\section{Use of insulin pumps with and without CGM in preschool children}

Recent technologies, such as pumps and CGM, can be particularly helpful to parents and caregivers of preschool children who are extremely dependent on fine-tuning of small insulin doses, both with regard to size and timing of insulin doses.

CGM can provide an effective mode of monitoring for low and high glucose levels, allowing for efficacious insulin adjustment. Regularly downloading data from the pump and CGM both at home and in clinic, allows patterns of dosing and glucose levels to be recognizable. An insulin pump system is available that can switch off insulin delivery when glucose levels, as measured by CGM, are predicted to become low, and thus reduce the risk and duration of hypoglycemia (128). Remote monitoring of the CGM screen is an emerging technology that will enable parents and other caregivers to take part of the child's glucose levels in real-time, while at day-care or preschool. On the other hand, insulin pumps and CGM are associated with increased cost and may increase the provider burden; insulin pumps may also carry additional risks associated with pump and infusion set malfunctions.

- Preschool children are unique consumers of novel insulin delivery and device technologies, as they are dependent on caregivers for all aspects of device use.

- Insulin doses in preschool children need to be modified frequently as children of this age are growing rapidly and have changing patterns of eating and sleeping.

- The decrease in size of insulin pumps and CGM devices (including the infusion sets/sensors) over the past few years make these therapies more acceptable for preschool children.

- The safety of insulin pump and CGM use in this population appears to be similar to that seen in other age groups.

- It is essential for the family to have access to blood ketone testing to detect problems with the supply of insulin from the pump. See the section on ketone monitoring below and the ISPAD guideline on sick days (129).

- Always give extra insulin with a pen or syringe in case of suspicion of problems with insulin delivery from the pump.

- If the child is prone to ketosis, replacing part of the overnight basal (30-40\%) with a small dose of long-acting insulin (detemir or glargine) may help, but might also reduce the flexibility in basal insulin administration by temporary basal rates.

- Parents of preschool children who switch from multiple daily injections to insulin pumps report more flexibility and freedom, as well as less stress and anxiety related to their child's care (130). 
- Data suggest a decrease in $\operatorname{HbA1c}(125,131)$ and reductions in rates of severe hypoglycemia $(93,131)$ after implementation of insulin pumps in preschool children.

- Insulin pump features that enable automatic bolus calculations based on insulin sensitivity factors and insulin to carbohydrate ratios can aid caregivers in insulin administration. A phone app can also be used for calculation of bolus doses of insulin.

- Insulin pump therapy may be effective in helping to manage toddler-eating behaviors by facilitating split bolus dosing.

- The pump calculates "insulin on board", i.e. how many units from a previous dose of insulin that still exerts a glucose-lowering effect.

- Although CGM provides an overwhelming amount of data, it is important to look for daily patterns (for example the "modal day" when downloading data), and adjust insulin-to-carbohydrate ratios and correction factors only after a repeated pattern has been found.

- The frequency of insulin pump and CGM use varies between centres. Barriers to the use of these treatment options in preschool children need to be explored.

\section{Skin Care}

There are very few data on special considerations regarding skin care in preschool children with type 1 diabetes but CGM-related skin problems seem to be most common in very young users. CGM-related skin problems are not associated with atopy (132). In general, recommendations for site use (including site selection, site preparation, site rotation) are similar as for older children. Many preschool children receive insulin injections and insert infusion sets and CGM sensors in their buttocks, an area often covered by a diaper. The abdomen, upper arm, and upper thigh regions are also commonly used. For children under the age of 6 using insulin pumps, data suggest that rates of scarring and lipohypertrophy are high (50\% and $45 \%$ respectively) but not different than in older children (133).

- Injection, infusion, and CGM sites should be properly prepared and regularly rotated in order to reduce the likelihood of lipohypertrophy, superficial scarring, infection, rashes, eczema and dry skin.

- Injection, infusion and CGM sites should be inspected by diabetes team members at every visit to the clinic to detect any skin problem or lipo-hyper/hypo-trophy early, in order to treat promptly).

- The use of pumps and CGM are often limited by skin reactions to the adhesive. Prepare the site a few days prior to insertion by the use of a skin moistener that preserves water. Topical cortisone (group I or II) can be used to treat eczema and break the vicious circle of itching after removal.

\section{Ketone monitoring}

Measuring ketone bodies in blood (betahydroxybutyrate, BOHB) should be recommended as the primary method of detecting and monitoring ketosis in preschool children with type 1 diabetes, se the ISPAD Guidelines on Sick days (129). Measurement of acetoacetate in urine can be used as an alternative, but gives less precise information. As preschool children do not urinate on command, especially when sick, results from blood ketone testing will be more easily available both for the child and parent. Blood ketone testing also give the health care professional much better information to provide advice over the phone or in the emergency room. 
Ketones should be monitored when there is a suspicion of lack of insulin raised either by high blood glucose (two values above $14 \mathrm{mmol} / \mathrm{l}$ within two hours that does not decline on a correction insulin dose) or when the child shows symptoms suggestive of ketosis (vomiting, nausea, stomach pain, fever, "unclear illness").

Elevated glucose levels and ketone levels suggest lack of insulin and should promptly be treated with injection of insulin $0.1 \mathrm{U} / \mathrm{kg}$ (or $10 \%$ of TDD) every second hour until BOHB is below $0.5 \mathrm{mmol} / 1$. If levels are above $3.0 \mathrm{mmol} / 1$, the family should seek care immediately at an emergency room due to the high risk of ketoacidosis. Slightly elevated BOHB (usually $<1.0 \mathrm{mmol} / \mathrm{mol}$ ) in combination with normal or low plasma glucose indicates combined lack of carbohydrate and insulin, commonly associated with gastroenteritis in preschool children. This can most often be treated at home with ingestion of sugary fluids and administration of extra insulin subcutaneously. See the ISPAD Guidelines on Sick days for further advice (129).

Ketoacidosis is a life-threatening acute complication of diabetes that demands care at a skilled hospital unit. Six percent of children younger than six years in the US and 4\% of children in Germany/Austria (from data from the Type 1 Diabetes Exchange clinic registry and the Prospective Diabetes Follow-up Registry: DPV) have suffered from ketoacidosis during the last year (45). Education of the families on prevention of ketoacidosis is an essential part of diabetes care (134). See the ISPAD Guidelines on Diabetic Ketoacidosis for further advice (134).

\section{Hypoglycemia}

Hypoglycemia, including fear of hypoglycemia, is a limitation to striving for normoglycemia. The risk of hypoglycemia presents a major physiological and psychological barrier to achieving optimal glycemic control, and may result in significant emotional morbidity for patients and caregivers $(29,135,136)$. Young age is traditionally regarded as a marker of high risk of severe hypoglycemia during insulin treatment (29). The frequency of severe hypoglycemia has decreased over time in all children $(29,35,137,138)$. In Germany and Austria, fewer than $2 \%$ of children younger than six years with type 1 diabetes have experienced a severe hypoglycemic event with seizures/unconsciousness during the previous year; in US this figure is less than 3\% (122).

The erratic daily life of a preschool child (food intake, activity, sleep, sick days) has been regarded as the explanation for the historically high risk of severe hypoglycemia in preschool children with type 1 diabetes. Preschool children are not yet able to identify and articulate their symptoms and it can be very difficult for caregivers to detect these symptoms. Prolonged nocturnal hypoglycemia is not uncommon in children younger than seven years with type 1 diabetes as detected in CGM studies $(121,139,140,141)$, which is associated with a higher risk of severe hypoglycemia (140).

The fear of an hypoglycemic event, rather than the frequency of hypoglycemic events, is associated with higher HbA1c and poorer HRQoL (135). The role of fear of hypoglycemia cannot be underestimated for both children and their parents (136). Asking about frequency and severity of hypoglycemia is typical in a clinic visit, but it may also be helpful to ask about thoughts and feelings during and after the hypoglycemic event. Fear of nocturnal 
hypoglycemia is a particular challenge (136). Fear is not correlated with the numbers of hypoglycemic episodes, but is related to their severity, especially in mothers of children who have experienced a hypoglycemic seizure.

The use of insulin pumps and CGM has been reported to decrease the risk of hypoglycemia $(142,143)$. Insulin pumps with low glucose suspend features appear to further reduce the time spent in hypoglycemia $(144,145)$.

The comparison of data between the United States T1D Exchange and German/Austrian DPV registries showed that an $\mathrm{HbA} 1 \mathrm{c}$ of $<7.5 \%(<58 \mathrm{mmol} / \mathrm{mol})$ can frequently be achieved in children younger than six years with type 1 diabetes without an increased risk of severe hypoglycemia (122). In many countries, children younger than seven years most frequently have the lowest HbA1c. In Sweden, $74 \%$ of insulin treated children younger than seven years have $\mathrm{HbA1c}<7.4 \%$ ( $<57 \mathrm{mmol} / \mathrm{mol})$, and the overall frequency of severe hypoglycemia (seizures/unconsciousness) in the pediatric age is $3.2 \%$ (146).

For definitions and further information see the ISPAD Guidelines on Hypoglycemia (29).

\section{Treatment of mild hypoglycemia in infants and preschool children}

Oral glucose as gel or a drink $(0.3 \mathrm{~g}$ glucose $/ \mathrm{kg}$ bodyweight $)$ is the preferred method of hypoglycemia treatment $(29,147)$. This dose will raise blood glucose approximately 2.5-3.6 $\mathrm{mmol} / \mathrm{l}(45-64 \mathrm{mg} / \mathrm{dl})$ (29). It is important not to give too much carbohydrate when treating hypoglycemia, in order to avoid subsequent hyperglycemia. Giving something that contains fat (i.e. milk, chocolate) will slow down the gastric emptying, and cause a slower rise in blood glucose (148). Sucrose sweetened confectionary should not be routinely used to treat hypoglycemia, as it can lead to increased risk of dental caries and food refusal if the child learns that sweets are substituted for unconsumed food. It is important that hypoglycemia is not over-treated, as 5-7 g carbohydrate is usually adequate in raising the blood glucose to normal levels for small children using intensive therapy.

To treat hypoglycemia in breast- or formula-fed infants, carbohydrate gel, diluted juice or a glucose polymer from a spoon or bottle can be offered. Honey should not be given to infants younger than 1 year due to risk of botulism.

\section{Screening for associated diseases}

Early onset of type 1 diabetes is associated with a higher frequency of celiac disease compared with older children, which affects the treatment situation of the child $(149,150$, 151) and may influence the risk of complications and quality of life. Repeated screening for celiac disease, thyroid disease and other autoimmune disorders is essential (152).

\section{Living with diabetes in the family}

For people living with type 1 diabetes and their families, the management of the condition is complex and individual. Daily challenges imposed by type 1 diabetes include cognitive and emotional burdens that can take the form of increased vigilance to dietary intake, symptom monitoring and frustrations with blood glucose excursions. For caregivers of preschool children with type 1 diabetes, additional complexities are encountered, including the necessity to adapt to developmental changes to ensure adequate psychological adjustments for the child and themselves, and to facilitate care in the context of other care providers such as preschool staff (153). Clinicians need to be aware of the overwhelming sense of responsibility and 
worry which parents of preschool children with type 1 diabetes can feel. Parents who have access to a supportive network (relatives and/or friends) have lower risk of diabetes related stress and burn-out (124). It is important to educate secondary caregivers about type 1 diabetes and insulin treatment. Attention has to be given to the needs of the siblings of a child with type 1 diabetes.

As children grow, they understand more about health and illness. When appropriate, it needs to be explained that diabetes is not caused by eating too much sugar, and that you cannot catch diabetes from another person. This needs actively to be taught to friends and relatives as well to avoid common misconceptions about diabetes.

Parents are an integral part of the diabetes team and have the most important supportive role to play over the years as their children eventually learn to self-manage their diabetes.

Providing this support can be difficult when parents have their own stressors to deal with, and struggle with the constant vigilance needed to ensure the safety of their child. Dashiff et al (154) report that parents of older children with type 1 diabetes experience an ongoing struggle, worry and frustration about their parenting role. During young childhood, parents take responsibility for all diabetes-related tasks such as insulin administration, dosing calculations, blood glucose testing, and so on. It is important that they do this in a way that is neither threatening nor frightening for their child. Involving the child in aspects of diabetes management as soon as possible (for example finger pricks and carbohydrate counting) is recommended, so the child can begin to develop a sense of ownership/management of their own health. A supportive and emotionally warm parenting style is important for promoting improved quality of life for children with type 1 diabetes (155).

Establishing good habits in the early years will form the basis for optimal diabetes selfmanagement during adolescence and into adulthood $(2,90,104,105)$. In order to create an environment in which parents feel confident and comfortable, it is crucial that they are appropriately supported by all members of their multi-disciplinary team and that they have adequate access to appropriate support when they need it. The way that parents model diabetes-related tasks will have a direct impact on the way their children learn. Supporting parents towards a positive adjustment to living with diabetes will help them to effectively model those tasks and assignments involved in daily life with diabetes. It is important to engage both fathers and mothers in diabetes care from the onset, and to keep them both involved in everyday diabetes care throughout the childhood years.

* Parents express that it is important to explain to their child in very simple and clear terms what type 1 diabetes involves. There are certain aspects of diabetes management that are not negotiable (glucose checking, insulin injections/pump site changes, CGM use, etc), and the child needs to begin to understand that as early as possible. It is important to involve the child in diabetes management as soon as possible so they can begin to develop a sense of ownership/management of their own disease. Reinforcing such an attitude early on will help to shape the child's attitude and approach to diabetes in the future.

* Parents report that diabetes will often initially disrupt the normal parent-child relationship, as diabetes frequently comes first in the mind of the parent in response to a child's requests. It is important for parents to ask themselves, "If my child didn't have type 1 diabetes, would I say no to this request?", and thus strive to re-establish the normal parent-child relationship. 


\section{Screening children for psychosocial distress}

Regular screening of children for psychosocial distress is important to ensure that difficulties are identified early, and appropriate support and treatment plans established as soon as possible. Most preschool children are not able to complete questionnaires or report on their own level of emotional distress in a reliable manner until they are approximately 7-8 years of age. Therefore, either talking with them directly about how they feel, or asking their parents to report on their children's psychosocial well-being is recommended. For children that are older, there are several paediatric measures of depressive symptoms that are validated and reliable for use with children as young as 7 years of age, varying in length and depth of detail. These include the Children's Depression Inventory (CDI) (156) and the Center for Epidemiologic Studies - Depression (CES-D) scale (157). Both measures are self-reported questionnaires containing items on types of symptoms (e.g. sadness, low self-esteem) and functional areas (e.g. not having friends, schoolwork is not as good as it was before, arguing with others). Pediatric quality of life can be addressed by specific questionnaires such as the Pediatric Quality of Life Inventory (PedsQL) generic and Type 1 Diabetes modules (158). These measures offer a child self-report for youth ages 5-7 and also for youth ages 8-12. There are also parent proxy reports for children ages 5-12. Diabetes-specific emotional distress can be assessed in children ages 8-11 (PAID-C) and teens (PAID-T) and parent's diabetes-specific emotional distress can also be assessed (P-PAID-C and P-PAID-T) in measures developed by Weissberg-Benchell and colleagues. Similarly, diabetes-specific emotional distress can be assessed by the PAID-Parent scale developed by Markowitz et al (159).

Parental anxiety can have a direct and negative effect on diabetes management and health outcomes. There can often be a co-morbidity of depression, however they are two separate conditions and should be treated separately. They may act in opposite directions with regard to diabetes management and control, so we recommend assessing anxiety separately from depression. The CESD is often used as a measure of depressive symptoms in adults, and the Beck Depression as well as the Beck Anxiety scales are also often used. Worries about diabetes impact on glycaemic control in children and should be acknowledged and addressed.

\section{Preschool care}

Many preschools provide excellent care for children with type 1 diabetes. Parents and healthcare professionals should work together to overcome any difficulties and ensure the safety and well-being of the child with type 1 diabetes when cared for outside the home setting. It is crucial that every child is supported effectively to achieve their potential. Legislation protects children with type 1 diabetes in many countries. One example is the Equality Act 2010 (England, Scotland and Wales) which dictates that schools must make reasonable adjustments to ensure that children with disability not are put at a substantial disadvantage compared with their peers. For diabetes this means schools ensuring they have enough staff trained so that the child with diabetes can take part in all aspects of preschool and school life. Contingency plans must be in place to train replacement staff quickly. The Kids and Diabetes in Schools (KiDS) program of the International Diabetes Federation (IDF) offers education and guidance for families and school staff on ways to help children with type 1 diabetes manage in school. KiDS information is available in eight languages (as of September 2015) and can be accessed online at http://www.idf.org/education/kids.

In addition to ensuring the rights of the child with diabetes, it is important to create trust and cooperation between the preschool, the family and the diabetes team. An individually written 
diabetes management plan is helpful in this cooperation to help the child with type 1 diabetes (160). Both the parents and the diabetes team need to share the responsibility for educating the preschool institution, especially when the child is newly diagnosed with diabetes or when additional diagnosis such as celiac disease occurs. Preschool staff often find carbohydrate counting helpful as it gives them a tool to assess the dose of insulin to be given in relation to the food intake and current glucose level. In countries where there are no regulations to support the child with diabetes, the diabetes team together with the parent organisations should advocate for improved regulations.

* Parents express that while regulations certainly help to ensure documentation and agree upon daily care, maintaining a close relationship with the school (staff, teachers, etc) is equally if not more important to ensure effective daily management of their child's diabetes. Parents can be in very close contact with the school, including offering training sessions, educational materials for other parents etc, which will lead to better and more effective diabetes management. This helps them to feel more comfortable/less stressed when sending their child to preschool.

\section{Alternative and complementary therapies}

It occurs that families try alternative indigenous remedies and even discontinue insulin. This can be avoided if parents are counselled regarding the absolute necessity of insulin for the child's survival. Alternative therapies may be tolerated if important for the family as long as they do not interfere with the regular diabetes care, including insulin doses, blood glucose monitoring and healthy food choices, or impact the child's growth or development or deplete economic resources needed for insulin treatment.

\section{Care for the preschool child with type 1 diabetes in limited resources settings}

Whenever possible, the guidelines described above in the preceding sections should be followed.

It is important to remember that building a good rapport with the family and providing comprehensive diabetes education are inexpensive, and remain the most effective strategies to improve diabetes management by the family (37). Knowledge about the effects of insulin, food and physical activity on plasma glucose levels are essential to protect the child from acute and chronic complications of diabetes under all circumstances. The first few visits of the family is the most crucial in this regard. The child should preferably be hospitalized for 4-5 days and parents should be counselled and educated in detail.

The challenges in managing type 1 diabetes in the preschool child are several-fold higher in resource limited settings. Awareness, health infrastructure and number of medical professionals trained in the management of childhood diabetes are inadequate for a significant proportion of the population in many countries in South East Asia and sub-Saharan Africa. The diagnosis is often delayed, and may even be missed in some cases, resulting in death before diagnosis. Common misdiagnoses are gastroenteritis, pneumonia, asthma, urinary tract infection, genital tract infection (candidiasis), enuresis and malaria. Parents may take longer to come to terms with the diagnosis and the need for life-long insulin therapy. The financial implications of the condition add to the psychological distress brought about by the diagnosis. Risk of acute and chronic complications, as well as mortality is higher in these children due to sub-optimal management (161). In the US, young people of African descent have increased 
risk of short-term complications (ketoacidosis and severe hypoglycemia) when adjusted for socioeconomic status (162), and higher HbA1c even when adjusted for mean glucose levels (163). HbA1c was higher even when fasting glucose is $<7 \mathrm{mmol} / \mathrm{l}$ in black individuals both with and without diabetes compared to white, but the prognostic value of $\mathrm{HbA1c}$ for predicting cardiovascular disease, nephron- and retinopathy were similar (164).

The financial issues need to be addressed upfront by the treating team. The challenge of finding ways to support the families lies chiefly with the care providers. The team should be familiar with the governmental and non-governmental agencies in the area that may provide financial assistance for procuring insulin and glucose strips, and ensure that parents have access to these before the child is discharged home.

Most preschool children in resource-limited settings remain on Regular and NPH insulin administered by insulin syringes. With only these insulins available (as in the DCCT study), a multiple injection therapy with regular insulin for meals and NPH insulin at bedtime can be effective in teaching the family the relationship between insulin dose and carbohydrate content of the meal. Carbohydrate counting can be used in this situation. The challenge to overcome will be the lunchtime injection at school. It is very important to motivate and explain this to the school staff as the alternative of giving a twice daily mixture of Regular and NPH does not result in a physiological insulin profile. In a situation where food availability is unpredictable, a child on twice daily injections will experience hypoglycemia, while the child on multiple injections can adjust mealtime doses accordingly.

Few patients are able to afford analogue insulin and pen devices. The use of insulin pumps is affordable by a low percentage of the population. Administration of small doses is therefore a practical challenge. In young infants, parents may be taught to dilute insulin with normal saline (available in $10 \mathrm{ml}$ vials). The use of syringes with $30 \mathrm{U}$ in $0.3 \mathrm{ml}$ allows as well an accurate administration of half units, appropriate for most children. Similarly, use of CGM remains unavailable for most children with type 1 diabetes in resource-limited scenario, and frequent self-monitoring of blood glucose is the only method for monitoring glycemia. However, even this may not be feasible for some families due to the high cost of glucose strips. If possible, the child can be recommended a meal plan with a relatively consistent carbohydrate intake at meal and snack times during the day to match the insulin regimen. The family can be taught to have a high index of suspicion for hypoglycemia and treating it on suspicion, relying mostly on urinary glucose monitoring, and to use SMBG at least on sick days if available (165). With limited number of strips, the family can for example measure before and 2 hours after lunch one week, and before and after dinner the next to get a more stringent picture of the day compared to random checks.

Another issue that may compound the challenge in resource-limited settings is that some parents may have low levels of literacy and health literacy, meaning thereby that they cannot read the numbers on the insulin syringe and on the glucometer. For example, in India, literacy rate is $74.04 \%$ according to the $15^{\text {th }}$ official census in 2011 , (http://www.census2011.co.in/literacy.php). In such cases, it is helpful to identify a suitably literate relative, friend or neighbour who can undergo diabetes education along with the parents and assist them in the domiciliary management. The parents should also be encouraged to learn the basics of reading and writing. In case of low literacy, a simpler insulin regime such as twice daily dosing with pre-mixed insulin can be given. Hearing the number of clicks from an insulin pen can obviate the need to read the number of units.

Teaching the parents to recognise 'Hi' and 'Lo' on glucometer, to treat hypoglycemia based on symptoms alone, and to recognize hyperglycemia and ketonuria by urinary strips is also 
useful to prevent life-threatening episodes. Vomiting in a child with diabetes should always be regarded as imminent ketoacidosis, and appropriate treatment should be sought immediately in the absence of knowledge and diagnostic measurements. If the child is not feeling well with other symptoms, the first line of treatment should be something containing sugar to treat impending hypoglycemia. This should be well known by all the older children and adults that are close to the child with diabetes, and they should know where to readily find a source of sugar.

To conclude, the goals of management of type 1 diabetes in resource-limited settings must be situated in the context of the resource limited environment and based on the family's educational and financial status. Avoidance of acute life-threatening complications and continuation of regular treatment and follow-up are the immediate goals.

\section{Future needs of preschool children with type 1 diabetes}

"Diabetes during early childhood creates a psychosocial challenge to the families of these children. Successful management of infants and toddlers with diabetes depends on a well functioning and educated family, the availability of a diabetes health care team experienced in the treatment of these youngsters, and the involvement of the extended family, child care personnel and others who play a role in their daily care" (Daneman 1999) (166).

The addition of new tools should enable families living with type 1 diabetes to provide increasingly effective therapy and support for preschool children with diabetes. The cognitive, motor and social immaturity, as well as the small body size of preschool children must be considered when designing new equipment, including sensors, insulin pumps and (semi) closed-loop solutions for insulin delivery.

It is important to include children younger than seven years in both epidemiological and clinical studies regarding treatment strategies and tools (both technical equipment and pharmacological) and outcomes; moreover, when the youngest children with type 1 diabetes are included in these studies, data regarding children with early-onset diabetes must be presented separately to enable subgroup analysis. Children younger than seven years with type 1 diabetes constitute only approximately $10 \%$ of the population of all children and adolescents with type 1 diabetes, but in many countries the incidence in this subgroup is increasing most quickly. Collaboration between centres is thus necessary in order to conduct studies that are sufficiently powered.

\section{References:}

1. Rubio-Cabezas O, Hattersley AT, Njølstad PR, Mlynarski W, Ellard S, White N, Chi DV, Craig ME. The Diagnosis and Management of Monogenic diabetes. Pediatric Diabetes 2014: 15(Suppl. 20): 47-64.

2. Antonovsky, A, Unraveling the mystery of health, Jossery-Bass Inc. Publishers 1987.

3. Gruszfeld D, Socha P. Early nutrition and health: short- and long-term outcomes. World Rev Nutr Diet. 2013;108:32-39

4. Khadilkar VV, Parthasarathy LS, Mallade BB, Khadilkar AV, Chiplonkar SA, Borade AB. Growth status of children and adolescents with type 1 diabetes mellitus. Indian J Endocrinol Metab. 2013 17(6):1057-60 
5. Kim MS, Quintos JB. Mauriac syndrome: growth failure and type 1 diabetes mellitus. Pediatr Endocrinol Rev. 2008;5 Suppl 4:989-93

6. Prado EL, Dewey KG. Nutrition and brain development in early life. Nutr Rev.2014;72(4):267-84.

7. Kuzawa CW, Chugani HT, Grossman LI, Lipovich L, Muzik O, Hof PR, Wildman DE, Sherwood CC, Leonard WR, Lange N. Metabolic costs and evolutionary implications of human brain development. Proc Natl Acad Sci U S A. 2014 9;111(36):13010-5

8. Leonard WR, Snodgrass JJ, Robertson ML. Effects of brain evolution on human nutrition and metabolism. Annu Rev Nutr. 2007;27:311-27.

9. Brekke E, Morken TS, Sonnewald U. Glucose metabolism and astrocyte-neuron interactions in the neonatal brain. Neurochem Int. 2015;82:33-41.

10. Caravas J1, Wildman DE. A genetic perspective on glucose consumption in the cerebral cortex during human development. Diabetes Obes Metab. $2014 ; 16$ Suppl $1: 21-5$.

11. Morris AA. Cerebral ketone body metabolism. J Inherit Metab Dis. 2005;28(2):10921.

12. Northam E.A, Anderson P.J, Jacobs R, Hughes M, Warne G.L, Werther G.A. Neuropsychological profiles of children with type 1 diabetes 6 years after disease onset. DiabetesCare 2001: 24, 1541-1546.

13. Ryan, CM. Why is cognitive dysfunction associated with the development of diabetes early in life? The diathesis hypothesis. Pediatric Diabetes 2006:7, 289-297.

14. McCrimmon RJ, Ryan CM, Frier BM. Diabetes and cognitive dysfunction. Lancet 2012; 379: 2291-99

15. Asvold BO, Sand T, Hestad K, Bjorgaas MR. Cognitive function in type 1 diabetic adults with early exposure to severe hypoglycemia. A 16-year follow-up study. Diabetes Care 2010:33:1945-1947, 2010

16. Schoenle EJ, Schoenle D, Molinari L, Largo RH. Impaired intellectual development in children with type 1 diabetes: association with $\mathrm{HbA} 1 \mathrm{c}$, age at diagnosis and sex. Diabetologia 2002; 45: 108-14.

17. Gaudieri P.A., Chen R., Greer T. Holmes C.S. Cognitive function in children with type 1 diabetes: A metaanalysis. Diabetes Care 2008: 31(9), 1892-1897.

18. Bullmore E, Sporns O. The economy of brain network organization. Nature Reviews Neuroscience 2012: 13(5), 336-349. 
19. Giedd J.N, Rapoport J.L. Structural MRI of pediatric brain development: What have we learned and where are we going? Neuron 2010: 67(5), 728-734.

20. Bjørgaas MR. Cerebral effects of severe hypoglycemia in young people with type 1 diabetes. Pediatr Diabetes 2012: 13,100-107.

21. Perantie DC, Koller JM, Weaver PM, et al. Prospectively determined impact of type 1 diabetes on brain volume during development. Diabetes 2011:60, 3006-3014.

22. Ferguson SC, Blane A, Wardlaw J, et al. Influence of an early-onset age of type 1 diabetes on cerebral structure and cognitive function. Diabetes Care 2005:28 14311437.

23. Mauras N, Mazaika P, Buckingham B, Weinzimer S, White N.H, Tsalikian E, Hershey T, Cato A., Cheng P, Kollman C, Beck R, Ruedy K, Aye T, Fox L, Arbelaez A.M, Wilson D.M, Tansey M, Tamborlane W.V, Peng D, Marzelli M, Winer K, Reiss A.L, Network, D.R.i.C. (2015). Longitudinal assessment of neuroanatomical and cognitive differences in young children with type 1diabetes: Association with hyperglycemia. Diabetes 2015: 64(5), 1770-1779.

24. Lin A, Northam E.A., Rankins D., Werther G.A, Cameron, F.J. Neuropsychological profiles of young people with type 1 diabetes $12 \mathrm{yr}$ after disease onset. Pediatric Diabetes 2010:11, 235-243.

25. Perantie D.C, Lim A, Wu J, Weaver P, Warren S.L, Sadler M, Hershey T. (2008). Effects of prior hypoglycemia and hyperglycemia on cognition in children with type 1 diabetes mellitus. Pediatric Diabetes 2008:9(2), 87-95.

26. Cato MA, Mauras N, Ambrosino J, et al.; Diabetes Research in Children Network (DirecNet). Cognitive functioning in young children with type 1 diabetes. J Int Neuropsychol Soc 2014;20:238-247.

27. Cato MA, Mauras N, Mazaika P et al Longitudinal Evaluation of Cognitive Functioning in Young Children with Type 1 Diabetes over 18 Months. J Int Neuropsychol Soc . 2016 March ; 22(3): 293-302. doi:10.1017/S1355617715001289.

28. Delamater AM, de Wit M, McDarby V, Malik J, Acerini CL. Psychological care of children and adolescents with type 1 diabetes. Pediatric Diabetes 2014: 15 (Suppl. 20): 232-244

29. Ly TT, Maahs DM, Rewers A, Dunger D, Oduwole A, Jones TW. Assessment and management of hypoglycemia in children and adolescents with diabetes. Pediatr Diabetes. 2014;15:180-92

30. Rewers MJ, Pillay K, de Beaufort C, Craig ME, Hanas R, Acerini CL, Maahs DM. Assessment and monitoring of glycemic control in children and adolescents with diabetes. Pediatric Diabetes 2014: 15 (Suppl. 20): 102-114.

31. American Diabetes Association. Children and adolescents. Sec. 11. In Standards of Medical Care in Diabetes 2016. Diabetes Care 2016;39(Suppl. 1):S86-S93 
32. Chiang JL, Kirkman MS, Laffel LM, Peters AL, Type 1 Diabetes Sourcebook A. Type 1 diabetes through the life span: a position statement of the American Diabetes Association. Diabetes Care 2014;37:2034-54.

33. NICE guideline Diabetes (type 1 and type 2) in children and young people: diagnosis and management. nice.org.uk/guidance/ng18 (published: 26 August 2015).

34. Lange K, Swift P, Pańkowska E ISPAD Clinical Practice Consensus Guidelines 2014. Diabetes education in children and adolescents. Pediatr Diabetes. 2014;15(Suppl 20):77-85.

35. Rosenbauer J, Dost A, Karges B, Hungele A, Stahl A, Bächle C, et al. Improved metabolic control in children and adolescents with type 1 diabetes: a trend analysis using prospective multicenter data from Germany and Austria. Diabetes Care 2012;35:80-6.

36. Swift PGF, Skinner TC, de Beaufort CE, Cameron FJ, Åman J, Aanstoot HJ, et al. Target setting in intensive insulin management is associated with metabolic control: The Hvidoere Childhood Diabetes Study Group Centre Differences Study 2005. Pediatr Diabetes. 2010;11(4):271-8.

37. Cameron FJ, de Beaufort C, Aanstoot HJ, Hoey H, Lange K, Castano L, et al. Lessons from the Hvidoere International Study Group on childhood diabetes: Be dogmatic about outcome and flexible in approach. Pediatr Diabetes. 2013;14(7):473-80.

38. De Beaufort CE, Lange K, Swift PG, Aman J, Cameron F, Castano L, et al. Metabolic outcomes in young children with type 1 diabetes differ between treatment centers: The Hvidoere study in young children 2009. Pediatr Diabetes. 2013;14(6):422-8.

39. Ceriello A, Ihnat M. "Glycaemic variability": A new therapeutic challenge in diabetes and the critical care setting. Diabet Med. 2010;27(8):862-7.

40. Virk S, Donaghue K, Cho Y, Benitez-Aguirre P, Hing S, Prykel A, Chan A, Craig M. Association Between HbA1c Variability and Risk of Microvascular Complications in Adolescents with Type 1 Diabetes J Clin Endocrinol Metab 2016 doi: $10.1210 /$ jc. $2015-3604$

41. McNeilly AD, McCrimmon RJ. The Scylla and Charybdis of glucose control in childhood type 1 diabetes? Pediatr Diabetes. 2015 ;16(4):235-41.

42. Shalitin S1, Phillip M. Which factors predict glycemic control in children diagnosed with type 1 diabetes before 6.5 years of age? Acta Diabetol. 2012;49(5):355-62.

43. Soupal J, Skhra J, Fajman M, Horova E, Mraz M, Skhra J, Prazny M. Glycemic variability is higher in type 1 diabetes patients with microvascular complications irrespective of glycemic control. Diabetes Technology \& Therapeutics. 2014; 16:4 198-203

44. Smart CE, Annan F, Bruno LPC, Higgins LA, Acerini CL. Nutritional management in children and adolescents with diabetes. Pediatric Diabetes 2014: 15 (Suppl. 20): 135153.

45. Maahs D et al., on behalf of the National Paediatric Diabetes Audit and the Royal College of Paediatrics and Child Health, the DPV Initiative, and the T1D Exchange 
Clinic Network. Rates of diabetic ketoacidosis: International comparison with 49,859 pediatric patients with Type 1 Diabetes from England, Wales, the U.S., Austria, and Germany. Diabetes Care 2015;38:1876-1882

46. The Diabetes Control and Complications Trial Research Group. The effect of intensive treatment of diabetes on the development and progression of long-term complications in insulin-dependent diabetes mellitus. N Engl J Med. 1993;329(14):977-86.

47. Nathan DM, for the DCCT/EDIC Research Group The Diabetes Control and Complications Trial/Epidemiology of Diabetes Interventions and Complications Study at 30 Years: Overview. Diabetes Care 2014;37:9-16

48. Edge J, James T, Shine B. Persistent individual tracking within overall improvement in HbA1c in a UK paediatric diabetes clinic over 15-years. Diabet Med. 2010;27(11):1284-8.

49. Hofer SE et al. Tracking of metabolic control from childhood to young adulthood in type 1 diabetes. J Pediatr. 2014;165(5):956-61.

50. Danne T, Mortensen HB, Hougaard P, Lynggaard H, Aanstoot HJ, Chiarelli F, et al. Persistent differences among centres over 3 years in glycemic control and hypoglycemia in a study of 3,805 children and adolescents with type 1 diabetes from the Hvidore Study Group. Diabetes Care. 2001;24(8):1342-7.

51. Lawes T, Franklin V, Farmer G. HbA1c tracking and bio-psychosocial determinants of glycaemic control in children and adolescents with type 1 diabetes: Retrospective cohort study and multilevel analysis. Pediatr Diabetes. 2014;15(5):372-83.

52. Samuelsson U, Steineck I, Gubbjornsdottir S. A high mean-HbA1c value 3-15months after diagnosis of type 1 diabetes in childhood is related to metabolic control, macroalbuminuria, and retinopathy in early adulthood-a pilot study using two nationwide population based quality registries. Pediatr Diabetes. 2014;15(3):229-35.

53. Lachin JM, White NH, Hainsworth DP, Sun W, Cleary PA, Nathan DM for the Diabetes Control and Complications Trial (DCCT)/Epidemiology of Diabetes Interventions and Complications (EDIC) Research Group. Effect of intensive diabetes therapy on the progression of diabetic retinopathy in patients with type 1 diabetes: 18 years of follow-up in the DCCT/EDIC. Diabetes. 2015 Feb;64(2):631-42.

54. Lind M, Odén A, Fahlén M, Eliasson B. The shape of the metabolic memory of HbA1c: Re-analysing the DCCT with respect to time-dependent effects. Diabetologia. 2010;53(6):1093-8.

55. Bailey CJ, Day C. Glycaemic memory. Br J Diabetes Vasc Dis. 2008;8(5):242-7.

56. Donaghue KC, Wadwa RP, Dimeglio LA, Wong TY, Chiarelli F, Marcovecchio ML, Salem M, Raza J, Hofman PL, Craig ME. Microvascular and macrovascular complications in children and adolescents. Pediatric Diabetes 2014: 15 (Suppl. 20): 257-269.

57. Olsen BS, Sjolie AK, Hougaard P, Johannesen J, Marinelli K, Jacobsen BB, Mortensen HB. The significance of the prepubertal diabetes duration for the 
development of retinopathy and nephropathy in patients with type 1 diabetes. J Diabetes Complications 2004;18:160-4.

58. Cho YH, Craig ME, Donaghue KC Puberty as an accelerator for diabetes complications. Pediatric Diabetes 2014: 15: 18-26.

59. Salardi S, Porta M, Maltoni G, Rubbi F, Rovere S, Cerutti F, Iafusco D, Tumini S, Cauvin V; Diabetes Study Group of the Italian Society of Paediatric Endocrinology and Diabetology. Infant and toddler type 1 diabetes: complications after 20 years' duration.Diabetes Care. $2012 ; 35(4): 829-33$

60. Donaghue KC, Fung AT, Hing S, Fairchild J, King J, Chan A, Howard NJ, Silink M. The effect of prepubertal diabetes duration on diabetes. Microvascular complications in early and late adolescence. Diabetes Care. 1997;20(1):77-80.

61. Holl RW, Lang GE, Grabert M, Heinze E, Lang GK, Debatin KM. Diabetic retinopathy in pediatric patients with type-1 diabetes: effect of diabetes duration, prepubertal and pubertal onset of diabetes, and metabolic control. J Pediatr. 1998;132(5):790-4.

62. Anderzén J, Samuelsson U, Gudbjörnsdottir S, Hanberger L, Åkesson K. Teenagers with poor metabolic control already have a higher risk of microvascular complications as young adults. J Diabetes Complications. 2015 Dec 8. pii: S1056-8727(15)00486-9. doi: 10.1016/j.jdiacomp.2015.12.004. [Epub ahead of print]

63. Danne T, Bangstad H-J, Deeb L, Jarosz-Chobot P, Mungaie L, Saboo B, Urakami T, Battelino T, Hanas R. Insulin treatment in children and adolescents with diabetes. Pediatric Diabetes 2014: 15 (Suppl. 20): 115-134.

64. Hanas R. Reducing injection pain in children and adolescents with diabetes: a review of indwelling catheters. Pediatric Diabetes 2004: 5: 102 —111.

65. Danne T. et al Establishing glycaemic control with continuous subcutaneous insulin infusion in children and adolescents with type 1 diabetes: experience of the PedPump Study in 17 countries. Diabetologia 2008 Sep;51(9):1594-601.

66. Phillip M, Battelino T, Rodriguez H, Danne T, Kaufman F. Use of insulin pump therapy in the pediatric age-group: consensus statement from the European Society for Paediatric Endocrinology, the Lawson Wilkins Pediatric Endocrine Society, and the International Society for Pediatric and Adolescent Diabetes, endorsed by the American Diabetes Association and the European Association for the Study of Diabetes. Diabetes Care 2007;30(6):1653-1662.

67. DiMeglio LA, Boyd SR, Pottorff TM, Cleveland JL, Fineberg N, Eugster EA. Preschoolers Are Not Miniature Adolescents: A Comparison of Insulin Pump Doses in Two Groups of Children with Type I Diabetes. Journal of Pediatric Endocrinology and Metabolism 2004:17(6): 865-870. PMID: 15270404

68. Holterhus P-M et al. Predicting the optimal basal insulin infusion pattern in children and adolescents on insulin pumps. Diabetes Care 2013: 36:1507-1511

69. Nicolajsen T, Samuelsson A, Hanas R. Insulin Doses before and One Year after Pump Start: Children Have a Reversed Dawn Phenomenon. J Diab Sci Tech 2012;6:589-94. 
70. Mianowska B, Fendler W, Tomasik B, Młynarski W, Agnieszka Szadkowska A. Effect of insulin dilution on lowering glycemic variability in pump-treated young children with inadequately controlled type 1 diabetes. Diabetes Technology \& Therapeutics 2015:17:9

71. Elleri D, Allen JM, Tauschmann M, et al. Feasibility of overnight closed-loop therapy in young children with type 1 diabetes aged 3-6 years: comparison between diluted and standard insulin strength. BMJ Open Diabetes Research and Care 2014;2:e000040. doi:10.1136/bmjdrc-2014- 000040

72. Alemzadeh R, Hoffmann RG, Dasgupta M, Parton E. Development of optimal kids insulin dosing system formulas for young children with type 1 diabetes mellitus. Diabetes Technol Ther. 2012; 14:418-22

73. Thalange N, Bereket A, Larsen J, Hiort LC, Peterkova V. Treatment with insulin detemir or NPH insulin in children aged 2-5 yr with type 1 diabetes mellitus. Pediatr Diabetes 2011;12:632-41

74. Hathout EH, Fujishige L, Geach J, Ischandar M, Maruo S, Mace JW. Effect of therapy with insulin glargine (lantus) on glycemic control in toddlers, children, and adolescents with diabetes. Diabetes Technol Ther 2003;5:801-6.

75. Hanas R, Adolfsson P. Bolus Calculator Settings in Well-Controlled Prepubertal Children Using Insulin Pumps Are Characterized by Low Insulin to Carbohydrate Ratios and Short Duration of Insulin Action Time. J Diab Sci Tech 2016;

76. Andersen AJB, Ostenfeld A, Pipper CB, Olsen BS, Hertz AM, Jorgensen LK, Hogsmose J, Svensson J. Optimum bolus wizard settings in insulin pumps in children with Type 1 diabetes. Diabet Med. 2016 Jan 16. doi: 10.1111/dme.13064

77. Bell K, Smart C, Steil G, Brand-Miller J, King B, Wolpert H. Impact of fat, protein, and glycemic index on postprandial glucose control in type 1diabetes: implications for intensive diabetes management in the continuous glucose monitoring era. Diabetes Care 2015;38:1008-1015

78. Smart CE, Ross K, Edge JA, Collins CE, King BR. Children and adolescents on intensive insulin therapy maintain postprandial glycaemic control without precise carbohydrate counting Diabet Med. 2009 Mar;26(3):279-85

79. Smart CE, King BR, McElduff P, Collins CE. In children using intensive insulin therapy, a 20-g variation in carbohydrate amount significantly impacts on postprandial glycaemia. Diabet Med. 2012 Jul;29(7):e21-4

80. Hanas R, Lundqvist K, Sjöstrand A, Windell L. The Insulin on board setting in young prepubertal pumpers with good metabolic control does not match published pharmacodynamic data on insulin action time. Pediatric Diabetes 2013;14 (Suppl s18):abstract P239.

81. National Health and Medical Research Council (2012) Infant Feeding Guidelines. 
Canberra: Australian Government; National Health and Medical research council, www.nhmrc.gov.au

82. Patton SR, Dolan LM, Powers SW. Mealtime interactions relate to dietary adherence and glycemic control in young children with type 1 diabetes. Diabetes Care. 2006 May;29(5):1002-6

83. FAO/WHO Scientific Update on carbohydrates in human nutrition: conclusions Mann J, Cummings JH, Englyst H, Key T, Liu S, Riccardi G, Summerbell C, Uauy R, van Dam RM, Venn B, Vorster H and Wiseman M. European Journal of Clinical Nutrition (2007) 61 (Suppl 1), S132-S137

84. Carbohydrates and Health Scientific Advisory Committee on Nutrition 2015 TSO London, UK

85. Joint FAO/WHO/UNU Expert Consultation on Protein and Amino Acid Requirements in Human Nutrition (2002: Geneva, Switzerland) Protein and amino acid requirements in human nutrition : report of a joint FAO/WHO/UNU expert consultation.(WHO technical report series; no. 935)

86. Australian Dietary Guidelines National Health and Medical Research Council Commonwealth of Australia 2013.

87. Sundberg F, Augustsson M, Forsander G, Cederholm U, Axelsen M Children under the age of seven with diabetes are increasing their cardiovascular risk by their food choices. Acta Pædiatrica 2014 103, pp. 404-410.

88. Patton SR, Dolan LM, Chen M, Powers SW. Dietary adherence and mealtime behaviors in young children with type 1 diabetes on intensive insulin therapy. J Acad Nutr Diet. 2013 Feb;113(2):258-62

89. Mehta SN, Volkening LK, Quinn N, Laffel LM. Intensively managed young children with type 1 diabetes consume high-fat, low-fiber diets similar to age-matched controls. Nutr Res. 2014 May;34(5):428-35.

90. Kaikkonen J, Mikkilä V, Magnussen C, Juonala M, Viikari J, Raitakari O. Does childhood nutrition influence adult cardiovascular disease risk? - Insights from the Young Finns Study. Annals of Medicine 2013 Mar;45(2):120-8.

91. Cooke L The importance of exposure for healthy eating in childhood: a review. J Hum Nutr Diet 2007;20(4):294-301

92. duBose $\mathrm{S}$ et al on behalf of the Type 1 Diabetes Exchange Clinic Network and Diabetes Prospective Follow-up Registry. Obesity in youth with type 1 diabetes in Germany, Austria, and the United States. J Pediatr 2015;167:627-32

93. Kapellen TM, Heidtmann B, Bachmann J, Ziegler R, Grabert M, Holl RW. Indications for insulin pump therapy in different age groups: an analysis of 1,567 children and adolescents. Diabet Med 2007;24(8):836-842. 
94. Islam S, Abraham A, Donaghue K, Chan A, Lloyd M, Srinivasan S, Craig M, Plateau of adiposity in Australian children diagnosed with Type 1 diabetes: a 20-year study.Diabetic Medicine 2014 31(6):686-90

95. Christian M, Evans C, Hancock N, Nykjaer C, Cade J Family meals can help children reach their 5 A Day: a cross-sectional survey of children's dietary intake from London primary schools. J Epidemiol Community Health 2013;67 (4):332-8 .

96. Overby NC, Margeirsdottir HD, Brunborg C, Andersen LF, Dahl-Jørgensen K. The influence of dietary intake and meal pattern on blood glucose control in children and adolescents using intensive insulin treatment. Diabetologia. 2007 Oct;50(10):2044-51

97. Powers S, Byars K, Mitchell M, Patton S, Standiford D, Dolan L. Parent report of mealtime behavior and parenting stress in young children with type 1 diabetes and in healthy control subjects. Diab Care 2002; 25:313-18

98. Patton SR, Dolan LM, Powers SW. Differences in family mealtime interactions between young children with type 1 diabetes and controls: implications for behavioral intervention. J Pediatr Psychol. 2008 Sep;33(8):885-93

99. Patton SR, Piazza-Waggoner C, Modi AC, Dolan LM, Powers SW. Family functioning at meals relates to adherence in young children with type 1 diabetes. $\mathrm{J}$ Paediatr Child Health. 2009 Dec;45(12):736-41.

100. Patton SR, Dolan LM, Powers S. Dietary adherence and associated glycemic control in families of young children with type 1 Diabetes J Am Diet Assoc. 2007; 107:46-52.

101. Adamson M, Morawska A, Wigginton B. Mealtime duration in problem and non-problem eaters. Appetite. 2015 Jan;84:228-34

102. Kuhl ES, Clifford LM, Stark LJ. Obesity in preschoolers: behavioral correlates and directions for treatment. Obesity (Silver Spring). 2012 Jan;20(1):3-29

103. Kavey R-E, Allada, V, Daniels S, Hayman L, McCrindle B, Newburger J et al. Cardiovascular risk reduction in high-risk pediatric patients. A scientific statement from the American heart association expert panel on population and prevention science; the councils on cardiovascular disease in the young, epidemiology and prevention, nutrition, physical activity and metabolism, high blood pressure research, cardiovascular nursing, and the kidney in heart disease; and the interdisciplinary working group on quality of care and outcomes research. Endorsed by the American academy of pediatrics. Circulation 2006; 114:2710-2738. 
104. Telama R, Yang X, Leskinen E, Kankaapää A, Hirvensalo M, Tammelin T et al. Tracking of physical activity from early childhood through youth into adulthood. Medicine \& Science in Sports \& Exercise 2014;46(5):955-62.

105. Biddle S, Pearson N, Ross G, Braithwaite R. Tracking of sedentary behaviours in young people: A systematic review. Preventive Medicine 2010:51:345-351

106. Trigona B, Aggoun Y, Maggio A, Martin X, Marchand L, Beghetti M, FarpourLambert N. Preclinical noninvasive markers of atherosclerosis in children and adolescents with type 1 diabetes are influenced by physical activity. The journal of pediatrics 2010;157:533-539.

107. Hesketh K, Goodfellow L, Ekelund U, McMinn A, Godfrey K, Inskip H, Cooper C, Harvey N, van Sluijs E. Activity levels in mothers and their preschool children. Pediatrics 2014:133;4e973

108. Jago R, Sebire S, Edwards M, Thompson J. Parental TV viewing, parental selfefficacy, media equipment and TV viewing among preschool children. European Journal of Pediatrics 2013;172:1543-1545

109. Fisk C, Crozier S, Inskip H, Goddfrey K, Cooper C, Robinson S et al. Influences on the quality of young children's diets: the importance of maternal food choices. British Journal of Nutrition 2011;105:287-296

110. Raynor H, van Walleghen E, Osterholt K, Hart C, Jelalian E, Wing R, Goldfield G. The relationship between child and parent food hedonics and parent and child food group intake in children with overweight/obesity. Journal of the American Dietetic Association 2011;111:425-430

111. Brage S, Wedderkopp N, Ekelund U, Franks P, Wareham N, Andersen L, Froberg K. Features of the metabolic syndrome are associated with objectively measured physical activity and fitness in Danish children. The European Youth heart Study (EYHS). Diabetes Care 2004:27:2141-2148

112. Andersen B, Harro M, Sardinha L, Froberg K, Ekelund U, Brage S, Anderssen S. Physical activity and clustered cardiovascular risk in children: a cross-sectional study (The European Youth Heart Study). Lancet 2006;368:299-304

113. Steele R, van Sluijs E, Cassidy A, Griffin S, Ekelund U. Targeting sedentary time or moderate- and vigorous -intensity activity: independent relations with adiposity in a population-based sample of 10-y-old British children. The American Journal of Clinical Nutrition 2009;90:1185-92

114. Ekelund U, Luan J, Sherar L, Esliger D, Griew P, Cooper A, for the International Children's Accelerometry Database (ICAD) Collaborators. Moderate to vigorous physical activity and sedentary time and cardiometabolic risk factors in children and adolescents. JAMA 2012:307(7):704-712 
115. O`Neill J, Williams H, Pfeiffer K, Dowda M, McIver K, Brown W, Pate R. Young children's motor skill performance: relationships with activity types and parent perception of athletic competence. Journal of Science and Medicine in Sports 2013 Nov 15. pii: S1440-2440(13)00484-2

116. Beets MW, Bornstein D, Dowda M, Pate RR. Compliance with national guidelines for physical activity in U.S. preschoolers: measurement and interpretation. Pediatrics. 2011 Apr;127(4):658-64.

117. Tremblay et al Canadian Physical Activity Guidelines for the Early Years (aged 0-4 years) Appl. Physiol. Nutr. Metab. 37: 345-356 (2012)

118. Boldemann C, Blennow M, Dal H, Mårtensson F, Raustorp A, Yuen K, Wester U. Impact of preschool environment upon children's physical activity and sun exposure. Preventive Medicine 2006;42:301-308

119. Sundberg F, Forsander G, Fasth A, Ekelund U.Children younger than 7 years with type 1 diabetes are less physically active than healthy controls. Acta Paediatr. 2012 Nov;101(11):1164-9.

120. Jeha G, Karaviti L, Anderson B, O`Brian Smith E, Donaldson S, McGirk T, Haymond M. Continuous glucose monitoring and the reality of metabolic control in preschool children with type 1 diabetes. Diabetes Care 2004;27:2881-2886

121. Sundberg F, Forsander G. Detection and treatment efficacy of hypoglycemic events in the everyday life of children younger than 7 yr. Pediatric Diabetes. 2014 Feb;15(1):34-40.

122. Maahs DM, Hermann JM, DuBose SN, Miller KM, Heidtmann B, DiMeglio L a., et al. Contrasting the clinical care and outcomes of 2,622 children with type 1 diabetes less than 6 years of age in the United States T1D Exchange and German/Austrian DPV registries. Diabetologia. 2014;57(8):1578-85.

123. Barnard KD, Oliver N, Adolfsson P, Aldred C and Kerr D. Is iatrogenic sleep disturbance worth the effort in type 1 diabetes? Diabetic Medicine 2015, jan 19 doi: 10.1111/dme. 12699

124. Lindström C, Åman J, Lindahl Norberg A. Parental burnout in relation to sociodemographic, psychosocial and personality factors as well as disease duration and glycaemic control in children with type 1 diabetes mellitus. Acta Paediatrica 2011;100:1011-1017.

125. Blackman SM, Raghinaru D, Adi S et al. Insulin pump use in young children in the T1D Exchange clinic registry is associated with lower hemoglobin A1c levels than injection therapy. Pediatr Diabetes 2014;15(8):564-572. 
126. Tsalikian E, Fox L, Weinzimer S et al. Feasibility of prolonged continuous glucose monitoring in toddlers with type 1 diabetes. Pediatr Diabetes 2012;13(4):301307.

127. Englert K, Ruedy K, Coffey J, Caswell K, Steffen A, Levandoski L. Skin and adhesive issues with continuous glucose monitors: a sticky situation. J Diabetes Sci Technol 2014;8(4):745-751.

128. Choudhary P, Olsen B, Conget I, Vorrink L, Shin J, Lee S, Kaufman F. Performance of the Predictive Low Glucose Management Feature of the MiniMed 640G System in a User Evaluation Study. Diabetes (abstract 1080P ADA) 2015;64

129. Brink S, Joel D, Laffel L, Lee WW, Olsen B, Phelan H, Hanas R; International Society for Pediatric and Adolescent Diabetes. Sick day management in children and adolescents with diabetes. Pediatr Diabetes. 2014 Sep;15 Suppl 20:193-202

130. Sullivan-Bolyai S, Knafl K, Tamborlane W, Grey M. Parents' reflections on managing their children's diabetes with insulin pumps. J Nurs Scholarsh 2004;36(4):316-323

131. Mack-Fogg JE, Orlowski CC, Jospe N. Continuous subcutaneous insulin infusion in toddlers and children with type 1 diabetes mellitus is safe and effective. Pediatr Diabetes 2005;6(1):17-21.

132. Sundberg F, Viberg C, Soderlund T, Forsander G. CGM related skin problems are most common in very young users but not associated with atopy. Pediatric Diabetes 2015 (suppl 21) 50-150 (abstract P157).

133. Schober E, Rami B. Dermatological side effects and complications of continuous subcutaneous insulin infusion in preschool-age and school-age children. Pediatr Diabetes 2009;10(3):198-201.

134. Wolfsdorf JI, Allgrove J, Craig ME, Edge J, Glaser N, Jain V, Lee WWR, Mungai LNW, Rosenbloom AL, Sperling MA, Hanas R. A Consensus Statement from the International Society for Pediatric and Adolescent Diabetes: Diabetic ketoacidosis and hyperglycemic hyperosmolar state. Pediatric Diabetes 2014: 15 (Suppl. 20): 154179.

135. Johnson SR, Cooper MN, Davis E a., Jones TW. Hypoglycaemia, fear of hypoglycaemia and quality of life in children with Type 1 diabetes and their parents. Diabet Med. 2013;30(9):1126-31.

136. Barnard K, Thomas S, Royle P, Noyes K, Waugh N. Fear of hypoglycaemia in parents of young children with type 1 diabetes: a systematic review. BMC Pediatrics 2010: 10:50 doi:10.1186/1471-2431-10-50.

137. O'Connell SM, Cooper MN, Bulsara MK, Davis E a., Jones TW. Reducing rates of severe hypoglycemia in a population-based cohort of children and adolescents with type 1 diabetes over the decade 2000-2009. Diabetes Care. 2011;34(11):2379-80.

138. Cengiz E, Xing D, Wong JC, Wolfsdorf JI, Haymond MW, Rewers A, et al. Severe hypoglycemia and diabetic ketoacidosis among youth with type 1 diabetes in the T1D Exchange clinic registry. Pediatr Diabetes. 2013;14(6):447-54. 
139. Roup STG. Prolonged nocturnal hypoglycemia is Common During 12 Months of Continuous Glucose Monitoring in Children and Adults With Type 1 Diabetes. Diabetes Care. 2010;33(5):0-4.

140. Buckingham B, Wilson DM, Lecher T, Hanas R, Kaiserman K, Cameron F. Duration of nocturnal hypoglycemia before seizures. Diabetes care. 2008. p2110-2.

141. Golicki DT, Golicka D, Groele L, Pankowska E. Continuous Glucose Monitoring System in children with type 1 diabetes mellitus: a systematic review and meta-analysis. Diabetologia. 2008;51:233-40.

142. Phillip M, Danne T, Shalitin S, Buckingham B, Laffel L, Tamborlane W, et al. Use of continuous glucose monitoring in children and adolescents. Pediatr Diabetes. 2012;13(3):215-28.

143. Pickup JC, Sutton AJ. Severe hypoglycaemia and glycaemic control in Type 1 diabetes: meta-analysis of multiple daily insulin injections compared with continuous subcutaneous insulin infusion. Diabet Med. 2008;25:765-74.

144. Bergenstal RM, Klonoff DC, Garg SK, Bode BW, Meredith M, Slover RH, et al. Threshold-based insulin-pump interruption for reduction of hypoglycemia. N Engl J Med [Internet]. 2013;369:224-32.

145. Ly TT, Nicholas J a, Retterath A, Lim EM, Davis E a, Jones TW. Effect of sensor-augmented insulin pump therapy and automated insulin suspension vs standard insulin pump therapy on hypoglycemia in patients with type 1 diabetes: a randomized clinical trial. JAMA [Internet]. 2013;310:1240-7.

146. SWEEDIABKIDS yearbook 2014, available at www.ndr.nu

147. McTavish L, Wiltshire E. Effective treatment of hypoglycemia in children with type 1 diabetes: a randomized controlled clinical trial. Pediatric Diabetes 2011: 12: 381-387.

148. Brodows RG, Williams C, Amatruda JM. Treatment of insulin reactions in diabetics. JAMA 1984;252:3378-81.

149. Pham-Short A, Donaghue KC, Ambler G, Chan AK, Craig ME. Coeliac disease in type 1 diabetes from 1990 to 2009: higher incidence in young children after longer diabetes duration. Diabet Med 2012: 29: e286-e289.

150. Cerutti F, Chiarelli F, Lorini R, Meschi F,Sacchetti C. Younger age at onset and sex predict celiac disease in children and adolescents with type 1 diabetes. Diabetes Care 2004: 27: 1294-1298.

151. Fröhlich-Reiterer EE, Kaspers S, Hofer S et al. Anthropometry, metabolic control, and follow-up in children and adolescents with type 1 diabetes mellitus and biopsyproven celiac disease. J Pediatr 2011: 158:589-93.e2.

152. Kordonouri O, Klingensmith G, Knip M, Holl RW, Menon PSN, Aanstoot HJ, Craig ME. Other complications and diabetes-associated conditions in children and adolescents. Pediatric Diabetes 2014: 15 (Suppl. 20): 270-278.

153. Silverstein L. et al Care of children and adolescents with type 1 diabetes: A statement of the American Diabetes Association. Diabetes Care 2005 v28(1) pp:1186212

154. Dashiff C, Riley BH, Abdullatif H, Moreland E. Parents' experiences supporting self management of middle adolescents with type 1 diabetes mellitus. Pediat Nurs 2011, 37:304-310.

155. Botello-Harbaum M, Nansel T, Haynie DL, Iannotti RJ and Simons-Morton B. Responsive parenting is associated with improved type 1 diabetes-related quality of 
life. 2008, Child: care, health and development. DOI: 10.1111/j.13652214.2008.00855.x

156. Kovacs, M. (1992). Children's Depression Inventory. North Tonawanda, NY: Multi-Health Systems, Inc.

157. Radloff, L.S. (1977). The CES-D scale: A self-report depression scale for research in the general population. Applied Psychological Measurement, 1: 385-401.

158. Varni J, Burwinkle T, Jacobs J, Gottschalk M, Kaufman F, Jones K. The PedsQL in type 1 and type 2 diabetes: reliability and validity of the Pediatric Quality of Life Inventory Generic Core Scales and type 1 Diabetes Module. Diabetes Care 2003a; 26: 631-637.

159. Markowitz JT, Volkening LK, Butler DA, Antisdel-Lomaglio J, Anderson BJ, Laffel LMB. Re-examining a measure of diabetes-related burden in parents of young people with Type 1 diabetes: the Problem Areas in Diabetes Survey - Parent Revised version (PAID-PR). Diabet Med. 2012 April; 29(4): 526-530.

160. Siminerio LM et al. Care of Young Children With Diabetes in the Child Care Setting: A Position Statement of the American Diabetes Association. Diabetes Care 2014;37:2834-2842

161. Kumar KM, Saabo B, Rao PV et al. Type 1 diabetes: Awareness, management and challenges: current scenario in India. Indian J Endocrinol Metab. 2015;19:s6-8.

162. Willi SM, Miller KM, DiMeglio LA, Klingensmith GJ, Simmons JH, Tamborlane WV, Nadeau KJ, Kittelsrud JM, Huckfeldt P, Beck RW, et al. Racialethnic disparities in management and outcomes among children with type 1 diabetes. Pediatrics 2015;135:424-34.

163. Kamps JL, Hempe JM, Chalew SA. Racial disparity in A1C independent of mean blood glucose in children with type 1 diabetes. Diabetes Care 2010;33:1025-7.

164. Parrinello CM, Sharrett AR, Maruthur NM, Bergenstal RM, Grams ME, Coresh J, Selvin E. Racial Differences in and Prognostic Value of Biomarkers of Hyperglycemia. Diabetes Care 2015 Dec 17. pii: dc151360. [Epub ahead of print]

165. Rotchford AP, Rotchford KM, Machattie T, Gill GV. Assesing diabetic control - reliability of methods available in resource poor settings. Diabetic Medicine 2002;19:195-200.

166. Daneman D, Frank M, Perlman K, Wittenberg J. The infant and toddler with diabetes: Challenges of diagnosis and management. Paediatr Child Health. 1999 Jan;4(1):57-63. 